Research Article

\title{
Shaking Table Model Test and Seismic Performance Analysis of a High-Rise RC Shear Wall Structure
}

\author{
Shujin Li $\mathbb{D}$, Cai Wu $(\mathbb{D}$, and Fan Kong $\mathbb{1}$ \\ School of Civil Engineering and Architecture, Wuhan University of Technology, Luoshi Road No. 122, Wuhan 430070, China \\ Correspondence should be addressed to Shujin Li; sjli@whut.edu.cn
}

Received 13 February 2019; Revised 1 April 2019; Accepted 21 April 2019; Published 9 May 2019

Academic Editor: Evgeny Petrov

Copyright (c) 2019 Shujin Li et al. This is an open access article distributed under the Creative Commons Attribution License, which permits unrestricted use, distribution, and reproduction in any medium, provided the original work is properly cited.

\begin{abstract}
A building developed by Wuhan Shimao Group in Wuhan, China, is a high-rise residence with 56 stories near the Yangtze River. The building is a reinforced concrete structure, featuring with a nonregular T-type plane and a height $179.6 \mathrm{~m}$, which is out of the restrictions specified by the China Technical Specification for Concrete Structures of Tall Building (JGJ3-2010). To investigate its seismic performance, a shaking table test with a 1/30 scale model is carried out in Structural Laboratory in Wuhan University of Technology. The dynamic characteristics and the responses of the model subject to different seismic intensities are investigated via the analyzing of shaking table test data and the observed cracking pattern of the scaled model. Finite element analysis of the shaking table model is also established, and the results are coincident well with the test. An autoregressive method is also presented to identify the damage of the structure after suffering from different waves, and the results coincide well with the test and numerical simulation. The shaking table model test, numerical analysis, and damage identification prove that this building is well designed and can be safely put into use. Suggestions and measures to improve the seismic performance of structures are also presented.
\end{abstract}

\section{Introduction}

With the fast urbanization in China, the population growth in cities has led to ever-increasing demand for high-rise buildings to accommodate commercial and residential needs. High-rise buildings are very common in the densely populated cities all over the world, such as New York and London $[1,2]$. Accordingly, pertinent regulations have been developed to ensure the safety and reliability requirements of high-rise buildings. High-rise buildings that are designed and constructed according to codes and standards are deemed as complied with all regulatory requirements for the buildings. With the innovation and advancement of technology and materials, some high-rise buildings are planned and designed beyond the specifications of codes and standards, particularly for fast-developing countries such as China. To ensure the safe and reliable function of these buildings, it is imperative to investigate the behaviors of these buildings, in particular, the behavior under horizontal loadings such as wind and earthquake. It is also essential to identify and quantify if possible the characteristics of these buildings with a view to provide guidance for the future design of similar buildings.

The shaking table test is one of the most widely used techniques to assess the seismic performance of structures made of various materials. Commonly, it is widely used for assessing linear/nonlinear and elastic/inelastic dynamic response of structures. Martinelli et al. [3] presented the nonlinear dynamic response of a shaking table test for a fullscale seven-story reinforced concrete shear wall building, where four simulated earthquake records with increasing intensity were used as excitation. Saranik et al. [4] conducted a shaking table test to investigate the inelastic behavior of a two-story steel portal frame with bolted connections. Furthermore, it is not only used for structural dynamic tests but also for geotechnical behavior. Chen et al. [5] conducted a series of shaking table tests on a plaster model of a threestory and three-span subway station to investigate the seismic failure characteristics of the structure on the liquefiable ground. Lin et al. [6] undertook shaking table tests 
on three embankment slope models to study the seismic response of the embankment slope with different reinforcing schemes. The effectiveness of shaking table tests has also been studied. For example, Srilatha et al. [7] investigated the effect of frequency of base shaking on the dynamic response of unreinforced and reinforced soil slopes through a series of shaking table tests.

In shaking table tests, most researchers used scaled models as specimens. For example, Liu et al. [8] carried out shaking table tests on a 1/30 scaled model with and without base isolation bearings to assess the seismic performance of an isolated museum structure in high earthquake intensity regions. Lu et al. [9] tested a 1/50 scale high-rise building model on a shaking table for Shanghai World Financial Center Tower. The dynamic characteristics, seismic responses, and failure mechanism of the structure were investigated, and weak positions under seldom-occurred earthquakes were identified. Some researchers use prototype structures. For example, Lignos et al. [10] conducted a shaking table test on a fullscale high-rise building to demonstrate the effectiveness of the numerical models used. Graziotti et al. [11] performed a shaking table test on a two-story full-scale unreinforced masonry building to study its response, characteristics, damage mechanism, and evolution during the experimental phases.

The above literature review suggests that the shaking table test is an essential tool to assess and verify the dynamic behavior of structures. It is particularly imperative for those structures that exceed the limits of the specification of design codes and standards. It is with this regard that the present paper is in order. The Shimao Building (numbered 1-3 in the A2 block) is an iconic building in the central business district area of Wuhan, China, located on the bank of Yangtze River. It is a combined commercial and residential building with 56 stories. The lateral-force resisting system of the structure is the reinforced concrete (RC) shear wall with a height of $179.6 \mathrm{~m}$, exceeding the limit for high-rise buildings specified by Chinese Regulation Technical Specification for Concrete Structures of Tall Building (JGJ3-2010) [12]. Therefore, it is required to verify the structural seismic performance after the regular structural designing according to the codes. Besides, the irregular building shape in both plane and elevation complicates the analysis and determination of seismic resistance of the structure. To ensure the safety of the building, it is necessary to examine the behavior of the building under seismic loading. For this purpose, a shaking table test and its numerical analysis as well as structural damage identification were also conducted.

This paper focuses on the investigation of the seismic behavior of Shimao Building. Firstly, the results of a shaking table test on the 1/30 scale building model will be presented. The structural dynamic characteristics and the responses under different levels of earthquake loading will be investigated, and the failure mechanism and cracking pattern of the tested model will also be obtained. Then, the corresponding finite element model will be established to analyze its seismic performance. At last, a damage identification method based on the autoregressive (AR) model will also be presented to identify the damage of the test building. According to the analysis of experiment, finite element model, and theoretical identification of the test building, seismic performance of the prototype building will be obtained, and this study can make sure that the prototype building is designed reasonably and can be put into use safely. Finally, suggestions and measures to improve the prototype building seismic performance will also be presented.

\section{Design of Model Building}

2.1. Prototype Building. A 1/30 model of Shimao Building was designed and built for the shaking table test to represent the main characteristics of the prototype building. The experiment was undertaken in the laboratory of School of Civil Engineering and Architecture at Wuhan University of Technology, China. Figure 1 shows the representing plan and elevation of the prototype building. It can be seen from Figure 1(b) that the plan of the building is shaped as " $T$ " (maximum $32.85 \mathrm{~m}$ in length and maximum $19.5 \mathrm{~m}$ in width), and this shape of building may be susceptible to earthquake excitation. The vertical configuration of the building consists of a core tube accommodating staircase, lift well, and pipe shaft and shear walls located at the outer walls and some inner walls. The floors and roof of the building are reinforced concrete beam-slab structures. In addition, the upper (vertical) structure is fixed on the reinforced concrete base.

According to the "Technical Points (No. 65, 2015) of Special Inspection for Seismic Fortification of Out-of-Code High-rise Buildings" [13], issued by the Chinese Construction Ministry, the total height of the building $188.6 \mathrm{~m}$ (including the roof truss) with 56 stories exceeds the limit height of $170 \mathrm{~m}$ specified by the Class B shear wall structures according the Chinese code (JGJ3-2010) [12]. Furthermore, the building has a set back at the height of $128.35 \mathrm{~m}$ (the $41^{\text {st }}$ story), as shown in Figure 1, leading to a disagreement between the centroid and stiffness center. As a consequence, the eccentricity violates the requirements of seismic conceptual design that building structures should be symmetric in both plan and elevation. Overall, a shaking table test of this building can be quite necessary.

Dynamic characteristics of the prototype building were calculated through Chinese structural design software PKPM. Although the maximum seismic responses of the structure under Frequent 6 (defined at Section 3), shown in Table 1, satisfy the requirements of the code (specified by the Chinese Seismic Design Code of Building Structures), considering larger earthquakes happen and making extra certain, the shaking table test is still needed for further verification.

2.2. Similitude Law. In this paper, the similitude law is determined by the dimensional analysis method [14]. Firstly, similar conditions $\Pi$ are obtained, and then other similarity 


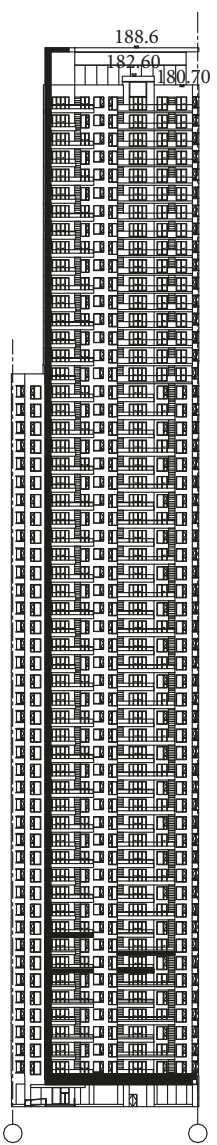

(a)

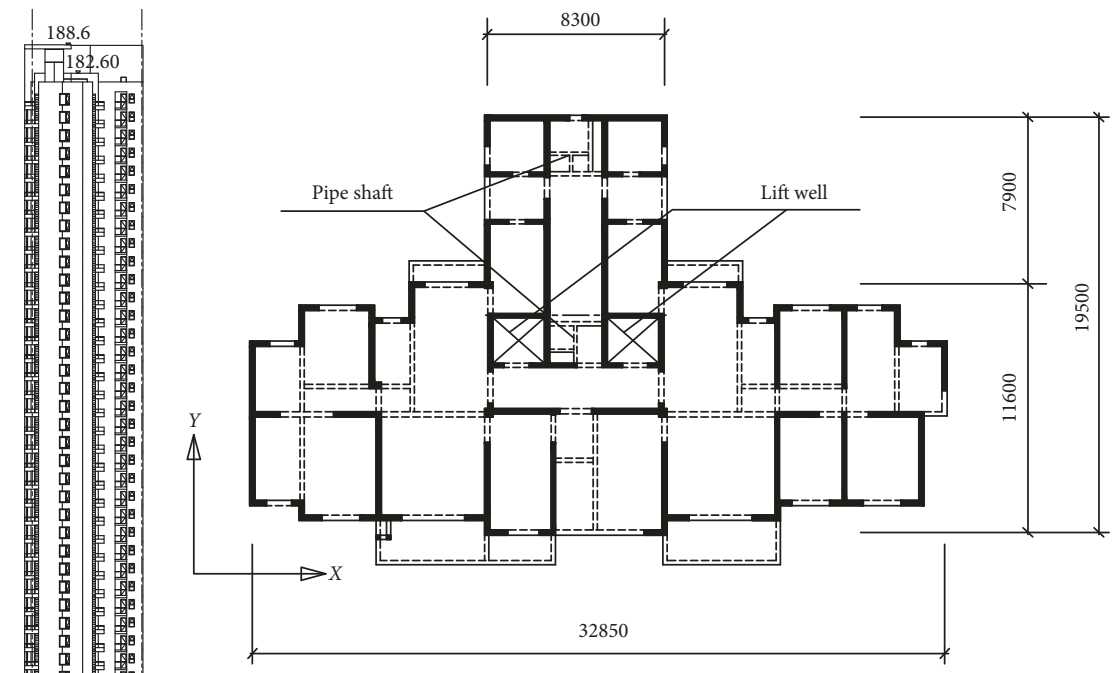

(b)

Figure 1: Sketch of prototype building: (a) elevation view; (b) floor plan below the $41^{\text {st }}$ story (units: $\mathrm{mm}$ ).

TABLe 1: Dynamic characteristics and seismic response of the prototype building.

\begin{tabular}{lccccc}
\hline Direction & Maximum lateral stiffness $(\mathrm{kN} / \mathrm{m})$ & Frequencies $(\mathrm{Hz})$ & Maximum displacement $(\mathrm{mm})$ & Story drift & Torsion displacement ratio \\
\hline$X$ & $1.09 \times 10^{8}$ & 2.9303 & 37.72 & $1 / 3500$ & 1.15 \\
$Y$ & $1.09 \times 10^{8}$ & 3.5724 & 54.16 & $1 / 2359$ & 1.19 \\
Torsion & & 1.7173 & & & \\
\hline
\end{tabular}

constants are obtained based on $\Pi$. Inertia force, restoring force, and gravity are required to be simulated in the test, and thus, elastic modulus $E$ and density $\rho$ of the model material are strictly controlled. The essential requirement is $(E / \rho a l)_{m}=(E / \rho a l)_{p}$, where the subscripts $m$ and $p$ represent the scaled model and the prototype building, respectively. That is,

$$
\frac{S_{E}}{S_{\rho} S_{a} S_{l}}=1,
$$

where $S_{E}, S_{\rho}, S_{a}$, and $S_{l}$ denote the similitude ratio of elastic modulus, equivalent density, acceleration, and geometry, respectively. In the present case, three controllable similitude ratios should be determined in advance to obtain others. Specifically, $S_{E}, S_{\rho}$, and $S_{l}$ are chosen in this paper, and thus, $S_{a}$ can be calculated using Equation (1).

Considering the shaking table size and the height requirement of the laboratory, the dimension scaling parameter
$S_{l}$ is chosen as $1 / 30$. Based on the tested characteristics of materials in the test, the similitude law of elastic modulus $S_{E}$ is determined as $1 / 3.05$. The total weight of the model (including self-weight and artificial mass) and prototype building are 3.06 ton and 40400 ton (including live load), respectively. Thus, the mass ratio $S_{m}$ is $1 / 13202.6$, and the similitude ratio of equivalent density $S_{\rho}$ can be obtained as 2.0245; all the main model similitude relationships and calculation formulas are shown in Table 2.

2.3. Model Constructing. Since the aim of the shaking table test is to investigate the seismic behavior of the original structure subjected to different intensity of earthquakes, including failure mode and mechanisms, it is necessary to use the same materials as the prototype building. The materials used for model construction (specimen) are microconcrete (mix proportion is shown in Table 3), galvanized 
TABle 2: Similitude law.

\begin{tabular}{|c|c|c|c|}
\hline Contents & Physical quantity & Similitude equation & Similitude law \\
\hline \multirow{4}{*}{ Geometric relationship } & Length & $S_{l}$ & $1 / 30$ \\
\hline & Linear displacement & $S_{X}=S_{l}$ & $1 / 30$ \\
\hline & Area & $S_{A}=S_{l}^{2}$ & $1 / 900$ \\
\hline & Angular displacement & 1 & 1 \\
\hline \multirow{4}{*}{ Material relationship } & Elastic modulus & $S_{E}$ & $1 / 3.05$ \\
\hline & Concrete strength & $S_{c}=S_{\sigma}$ & $1 / 6.92$ \\
\hline & Equivalent mass & $S_{m}=S_{\rho} \cdot S_{l}^{3}$ & $1 / 13202.6$ \\
\hline & Equivalent density & $S_{\rho}^{r}$ & 2.045 \\
\hline \multirow{5}{*}{ Dynamic relationship } & Period & $S_{T}=1 / S_{\omega}$ & 0.083 \\
\hline & Frequency & $S_{\omega}=\left[S_{\sigma} /\left(S_{\rho} S_{l}^{2}\right)\right]^{1 / 2}$ & 12.012 \\
\hline & Acceleration & $S_{a}=S_{l} \cdot S_{\omega}^{2}$ & 4.81 \\
\hline & Acceleration of gravity & $S_{g}$ & 1 \\
\hline & Force & $S_{F}=S_{E} S_{l}^{2}$ & $1 / 2745$ \\
\hline
\end{tabular}

TABle 3: Microconcrete mix proportion.

\begin{tabular}{lcc}
\hline Intensity level & Position & Mix proportion \\
\hline M10 & $1^{\text {st }} \sim 17^{\text {th }}$ floor & $1: 6.1: 0.8$ \\
M8 & $18^{\text {th }} \sim 37^{\text {th }}$ floor & $1: 5.6: 0.8$ \\
M6 & $38^{\text {th }} \sim$ top floor & $1: 5.0: 0.8$ \\
\hline
\end{tabular}

steel wires, and meshes which are similar to the materials in the prototype building. Ordinary Portland Cement P.O. 32.5 is chosen to construct concrete. A batch of specimens in the form of cubic and prism type were cast to measure the strength and elastic modulus of microconcrete. The testing method of the specimens strictly followed the requirements of the Standard for Test Methods of Concrete Structures (GB50152-2012) [15]. The microconcrete mix proportions are shown in Table 3. The elastic modulus of materials is shown in Table 4 . The height of the model is $6.437 \mathrm{~m}$, with $6.287 \mathrm{~m}$ for the model itself, and $0.15 \mathrm{~m}$ for the base. The photo of the completed model is shown in Figure 2.

\section{Testing Methodology}

3.1. Test Variables and Facility. The test variables include two types: different fortification intensity and different types of earthquake waves. According to related researches on the statistics of the peak acceleration of ground motions in China, the seismic intensity of a specific site exhibits the extreme distribution of the III type (Weibull distribution). The fortification intensity is defined as the intensity with $10 \%$ exceedance probability, which is also called as the moderate or basic intensity for simplicity. Similarly, the rare and frequent intensity is defined as the intensity with $2-3 \%$ and $65 \%$ exceedance probability, respectively. Furthermore, for the moderate intensity of a specific site, the frequent and rare intensity is about $1.55^{\circ}$ lower and $1^{\circ}$ higher than the moderate intensity, respectively. In this paper, the scaled building under investigation is located in Wuhan with Degree 6 as the fortification/basic intensity [16]. This intensity is associated with medium occurrence (10\%). Therefore, Moderate 6 means ground motion with Intensity 6 (the peak ground acceleration (PGA) is $0.05 \mathrm{~g}$ ) and Frequency 6 means ground motion with Intensity 4.45 (PGA
$0.018 \mathrm{~g}$ ), whereas Rare 6 means ground motion with Intensity 7 (PGA $0.1 \mathrm{~g}$ ). Ultralarge earthquakes are not specified in GB50011-2010 [17], and Rare 7 (actually Intensity 8) is introduced here for the purpose of studying the nonlinear or even collapse performance of the scaled building. For a chosen recorded seismic excitation, the similitude law (shown in Table 1) was used to scale the acceleration and time.

According to the dynamic characteristics and site condition of the prototype structure, three seismic runs are chosen for simulating the shaking table test input wave: (1) El Centro wave, with a peak acceleration of $3.41 \mathrm{~m} / \mathrm{s}^{2} ;$ (2) Taft wave, with a peak acceleration of $1.53 \mathrm{~m} / \mathrm{s}^{2}$; and (3) artificial seismic wave (USER1), supplied by the construction designers, with a peak acceleration of $0.18 \mathrm{~m} / \mathrm{s}^{2}$. The timehistory curves are shown in Figure 3. The main specifications of the shaking table used in the present experiment are shown in Table 5 .

3.2. Testing Procedure and Layout of Sensors. The testing procedure is shown in Table 6. It can be seen that the EI Centro wave is the first wave in each test condition, followed by the Taft wave and artificial seismic wave. Before and after inputting different fortification intensity seismic waves, low peak white noise excitation is conducted to measure the dynamic characteristics parameters such as natural frequency, mode, and damping ratio.

The main measurement of structural response is acceleration, displacement, strain, etc. Several acceleration sensors, displacement sensors, and strain gauges are arranged at the different heights of the model to measure the responses of the model structure under different seismic fortification intensities. Accelerations and displacements were measured by the large dynamic signal acquisition and analysis system DASP2003, developed by Orient Institute of Noise and Vibration. 14 acceleration sensors were used for different purposes, namely, 2 for measuring vertical accelerations, 10 for horizontal accelerations, and 2 for torsion of the building. Dynamic strain was obtained by the dynamic and static testing instrument DH3817. Five displacement sensors were used to measure the deformation along the direction of 
TABLE 4: Elastic modulus of materials.

\begin{tabular}{|c|c|c|c|}
\hline Floor & Prototype building $\left(\times 10^{4} \mathrm{~N} / \mathrm{mm}^{2}\right)$ & Test model $\left(\times 10^{4} \mathrm{~N} / \mathrm{mm}^{2}\right)$ & Ratio \\
\hline $1^{\text {st }} \sim 7^{\text {th }}$ & 3.55 & 1.21 & $1 / 2.93$ \\
\hline $8^{\text {th }} \sim 17^{\text {th }}$ & 3.45 & 1.21 & $1 / 2.85$ \\
\hline $18^{\text {th }} \sim 27^{\text {th }}$ & 3.35 & 1.09 & $1 / 3.07$ \\
\hline $28^{\text {th }} \sim 37^{\text {th }}$ & 3.25 & 1.09 & $1 / 2.98$ \\
\hline $38^{\text {th }} \sim 46^{\text {th }}$ & 3.15 & 0.95 & $1 / 3.32$ \\
\hline $47^{\text {th }} \sim$ top floor & 3.00 & 0.95 & $1 / 3.16$ \\
\hline
\end{tabular}

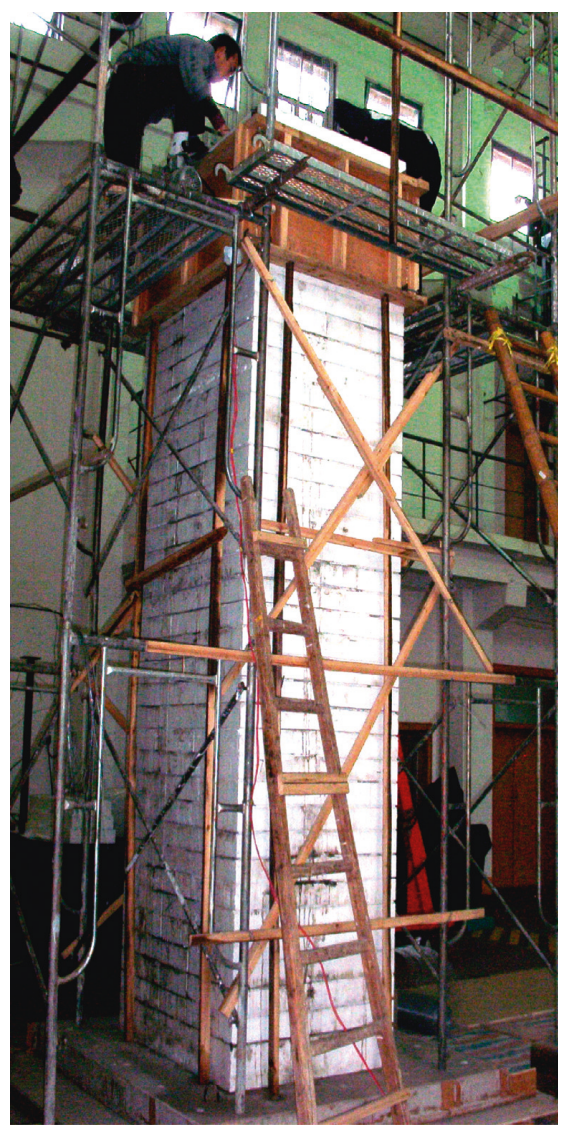

(a)

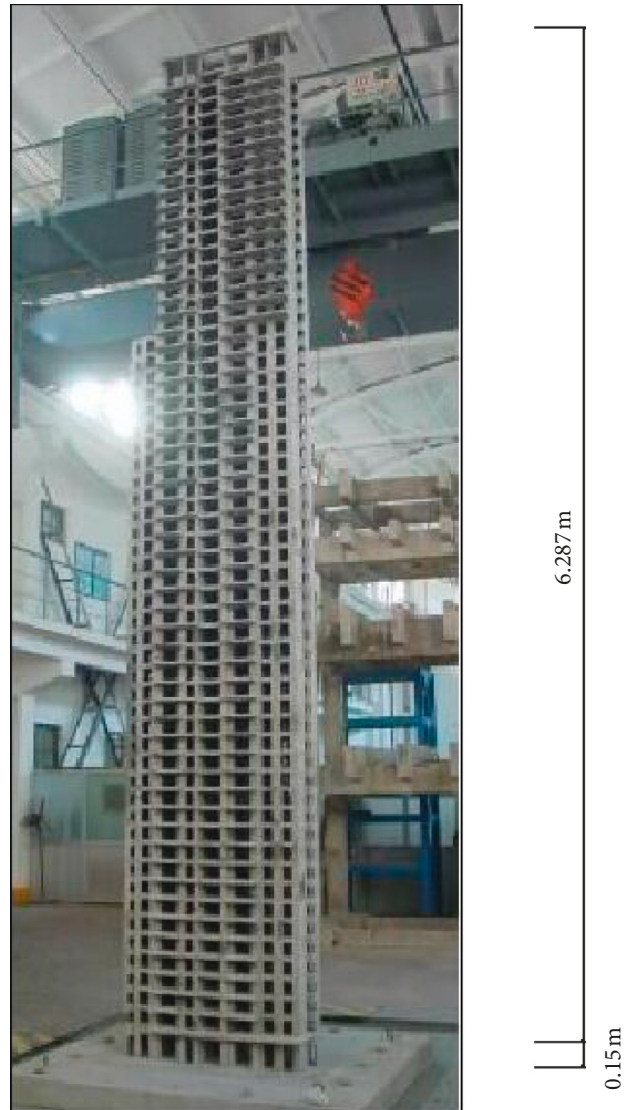

(b)

Figure 2: Pictures of the model: (a) model under construction; (b) completed model.

shaking. The positions of acceleration sensors and displacement sensors are shown in Figure 4.

\section{Test Results and Analysis}

4.1. Damage Patterns. When subjected to Frequent 6, there were no noticeable shaking and visible damages, it can be predicted that the test model can remain in a serviceable condition after Frequent 6 , and there was no damage. In the case of Moderate 6, the model responded with little vibration, but no cracks and structural damages, which may indicate that the model is still in serviceable conditions, and there was no need to strengthen. No visible cracks and significant damages occurred after Rare 6. However, the model responded with more vibrations and little crack, which indicated that the model was minor damaged, even though the test building was still in the serviceable condition.
Some part of it might need to be repaired. When subjected to Rare 7, it is observed that the model vibrates significantly, together with a large number of cracks in the upper part of the model and spalling of concrete. It can be concluded that the test building is not collapsed even when subject to Rare 7 but lost much of its lateral load resisting capacity. Since the prototype building is represented as the model, the damage pattern of the prototype building can be obtained. The damage of different floors after the test is shown in Figure 5.

4.2. Dynamic Characteristic. Low peak white noise excitation was used before and after seismic excitation for capturing the dynamic characteristic of the model. Results are shown in Table 7 . It can be seen that the natural frequencies of the test model maintain the same under Frequent 6, indicating linear behaviors of the structure in this stage. 


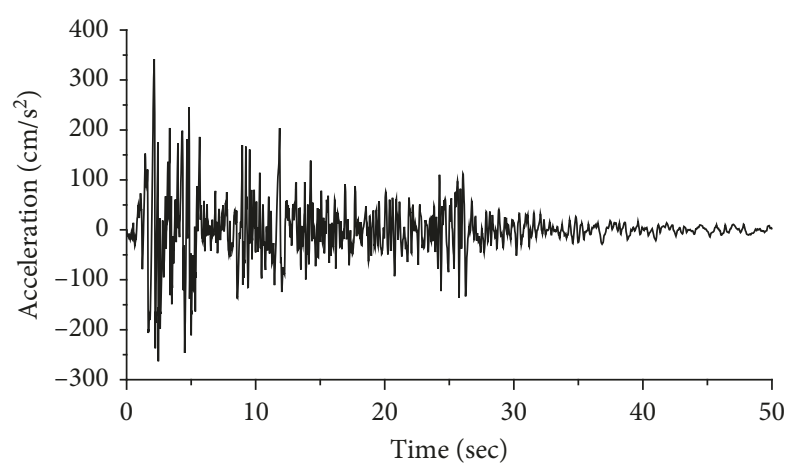

(a)

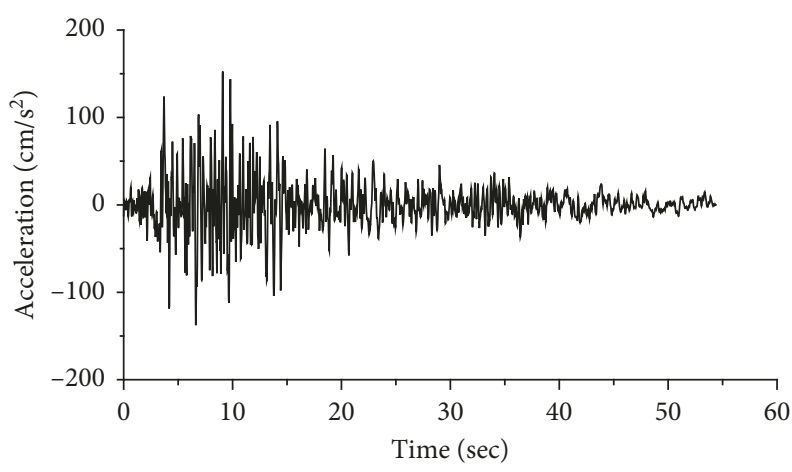

(b)

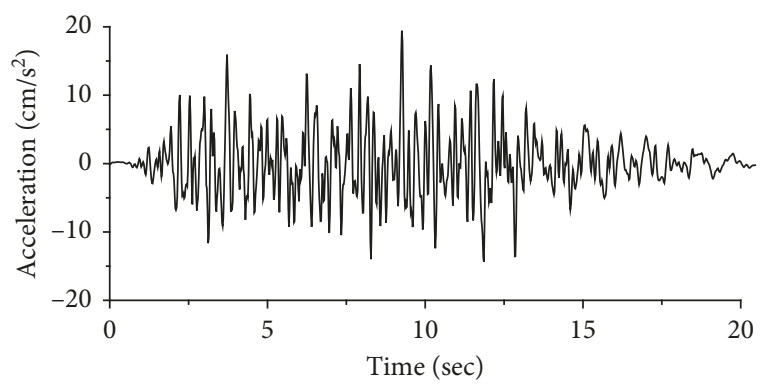

(c)

FIgure 3: Input seismic loading sequence: (a) El Centro wave; (b) Taft wave; (c) artificial seismic wave.

TABLE 5: Characteristics of the shaking table.

\begin{tabular}{lc}
\hline Item & Parameter \\
\hline Table size & $3 \times 3 \mathrm{~m}$ \\
Vibrating direction & One dimensional \\
Maximum displacement & $\pm 100 \mathrm{~mm}$ \\
Maximum velocity & $500 \mathrm{~mm} / \mathrm{s}$ \\
Maximum acceleration & $\pm 2.0 \mathrm{~g}$ (no load) $\pm 1.3 \mathrm{~g}$ (full load) \\
Maximum model mass & $10 \mathrm{t}$ \\
Frequency range & $0.4 \sim 40 \mathrm{~Hz}$ \\
\hline
\end{tabular}

TABLE 6: Sequence of the shaking table test.

\begin{tabular}{lcc}
\hline Test condition & Sequence number & Input seismic wave \\
\hline \multirow{3}{*}{ Frequent 6 } & 1 & White noise \\
& 2 & El Centro wave \\
& 3 & Taft wave \\
& 4 & Artificial seismic wave \\
Moderate 6 & 5 & White noise \\
& 6 & El Centro wave \\
& 7 & Taft wave \\
& 8 & Artificial seismic wave \\
Rare 6 & 9 & White noise \\
& 10 & El Centro wave \\
& 11 & Taft wave \\
Rare 7 & 12 & Artificial seismic wave \\
& 13 & White noise \\
& 14 & El Centro wave \\
& 15 & Taft wave \\
& 16 & White noise \\
\hline
\end{tabular}

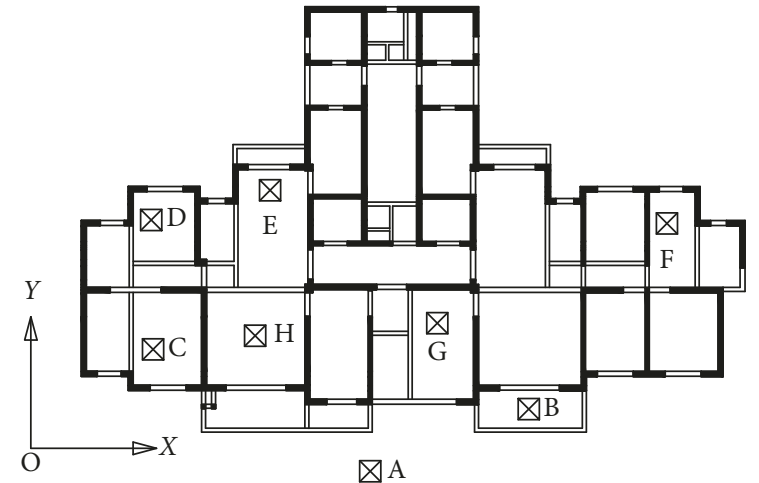

(a)

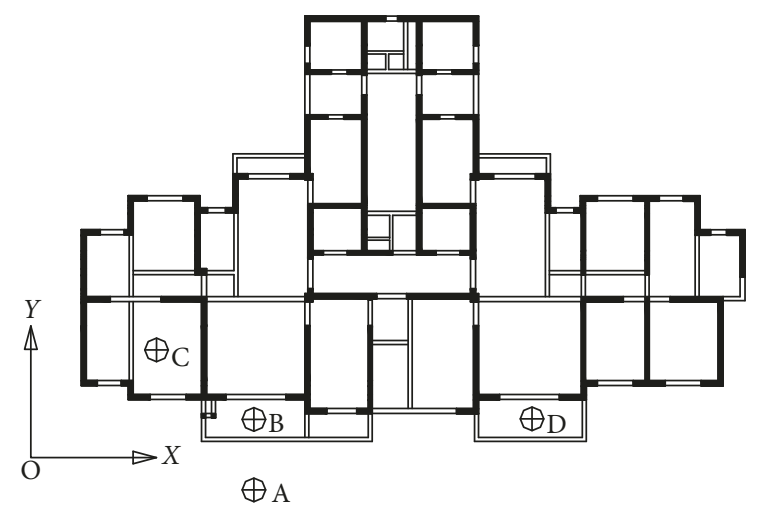

(b)

Figure 4: Positions of sensors: (a) acceleration sensors; (b) displacement sensors. 


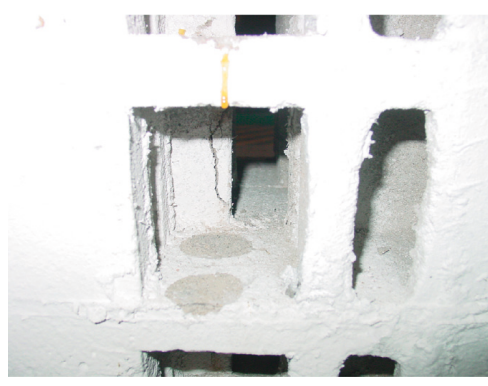

(a)

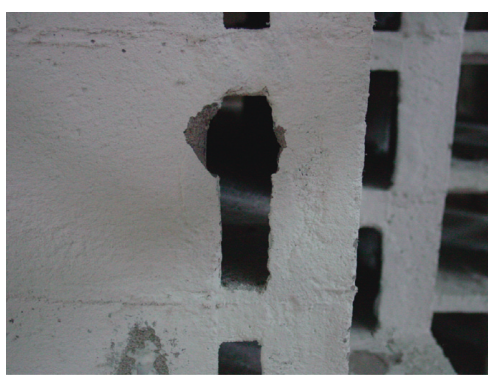

(b)

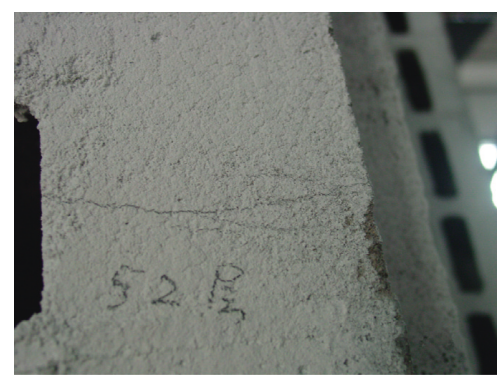

(c)

Figure 5: Damages of the test model after seismic input: (a) floors 1 to 3 ; (b) $42^{\text {nd }}$ floor; (c) $52^{\text {nd }}$ floor.

TABLe 7: Dynamic characteristic of the model before and after the earthquake excitation.

\begin{tabular}{|c|c|c|c|c|c|c|c|}
\hline \multirow{2}{*}{ Earthquake intensity } & \multirow{2}{*}{ Test items } & \multicolumn{3}{|c|}{$Y$} & \multicolumn{2}{|c|}{ Torsion } & \multirow{2}{*}{$\begin{array}{c}X \\
3^{\text {rd }} \text { order }\end{array}$} \\
\hline & & $1^{\text {st }}$ order & $2^{\text {nd }}$ order & $3^{\text {rd }}$ order & $1^{\text {st }}$ order & $2^{\text {nd }}$ order & \\
\hline \multirow{3}{*}{ Before earthquake } & Frequency $(\mathrm{Hz})$ & 2.54 & 12.11 & 29.41 & 7.62 & 21.30 & 3.71 \\
\hline & Period (s) & 0.3937 & 0.0826 & 0.0340 & 0.1312 & 0.0469 & 0.2695 \\
\hline & Damping ratio (\%) & 3.25 & 2.61 & 2.12 & & & 2.36 \\
\hline \multirow{3}{*}{ Frequent 6} & Frequency $(\mathrm{Hz})$ & 2.54 & 12.11 & 29.21 & 7.62 & 21.10 & \\
\hline & Period (s) & 0.3937 & 0.0826 & 0.0342 & 0.1312 & 0.0474 & \\
\hline & Damping ratio (\%) & 4.41 & 2.71 & 2.83 & & & \\
\hline \multirow{3}{*}{ Moderate 6} & Frequency $(\mathrm{Hz})$ & 2.54 & 11.92 & 28.72 & 7.52 & 20.91 & \\
\hline & Period (s) & 0.3937 & 0.0839 & 0.0348 & 0.1330 & 0.0478 & \\
\hline & Damping ratio (\%) & 4.20 & 3.04 & 3.37 & & & \\
\hline \multirow{3}{*}{ Rare 6} & Frequency $(\mathrm{Hz})$ & 2.44 & 11.33 & 27.75 & 7.30 & 19.93 & \\
\hline & Period (s) & 0.4098 & 0.0883 & 0.0360 & 0.1370 & 0.0502 & \\
\hline & Damping ratio (\%) & 4.01 & 3.11 & 3.35 & & & \\
\hline \multirow{3}{*}{ Rare 7} & Frequency $(\mathrm{Hz})$ & 2.34 & 10.75 & & 6.84 & 18.66 & \\
\hline & Period (s) & 0.4274 & 0.0930 & & 0.1462 & 0.0536 & \\
\hline & Damping ratio (\%) & 3.87 & 3.80 & & & & \\
\hline
\end{tabular}

Furthermore, the second- and the third-order frequencies of the test model decreased slightly after Moderate 6, reflecting slight decrease of the structure's stiffness. Next, after Rare 6, the natural fundamental frequency decreased by $3.9 \%$, indicating that damages may occur at a certain lateral-force resisting component of the model structure. Finally, after Rare 7, the natural frequencies of the test model decreased significantly. It can be inferred that the $1^{\text {st }}$ mode of the prototype structure is the $Y$ direction, the $2^{\text {nd }}$ mode is the $X$ direction, and the $3^{\text {rd }}$ mode is torsion. The ratio of the $1^{\text {st }}$ mode periods between torsion to the $Y$ and $X$ direction is 0.33 and 0.49 , respectively, which is far smaller than the limit value 0.85 given by the Chinese code (JGJ32010) [12]. Furthermore, after analyzing the structure stiffness degradation curves in accordance with the $1^{\text {st }}$ order natural frequencies of the model, it can be obtained that the stiffness of the structure declines with the increasing magnitude of earthquake excitation, with a minimum stiffness to $81.9 \%$.

4.3. Acceleration Response. Acceleration amplification factor is the ratio of the maximum absolute value of acceleration response of each story to the maximum input acceleration at the bottom of the model. This factor is of great significance to analyze the seismic performance of structures, describing how many times the accelerations at each story are amplified compared to the base seismic excitation. Hence, the acceleration amplification factor can be obtained through dividing the peak accelerations of the testing stories by the peak accelerations of the shaking table in this test. Then, the envelope diagram of the building in different test conditions can be drawn. Figure 6 shows the envelope of acceleration amplification factors in the main vibration direction ( $Y$ direction) with different seismic intensities, and the peak acceleration of some floors in a specific condition and acceleration amplification factor are listed in Table 8.

As can be seen, the acceleration amplification factors along the floors of the structure are nearly invariable except for the top floor, reflecting the lateral stiffness at different floors (except for the top floor) is uniformly distributed. Furthermore, the acceleration amplification factor was almost unchanged after suffering from Frequent and Moderate 6, which indicated that the lateral-force resisting components of the model are seldom damaged. However, the acceleration amplification factor increases sharply on the top floor and roofing layer, indicating that the whiplash effect cannot be ignored in this case. Usually when damages are increasing, the stiffness of structures is reducing, leading to the elastic-plastic phrase, which can result in a smaller acceleration amplification. It can be seen in Figure 6 that the 


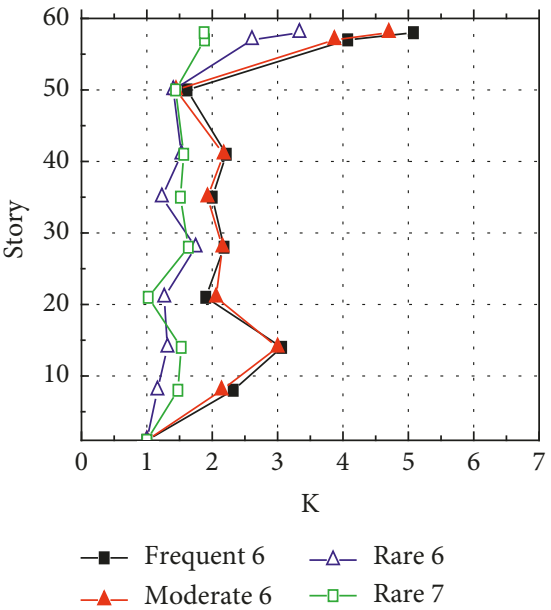

(a)

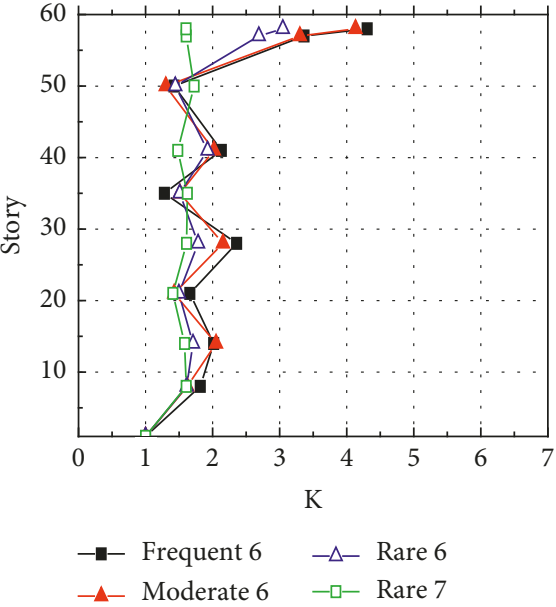

(b)

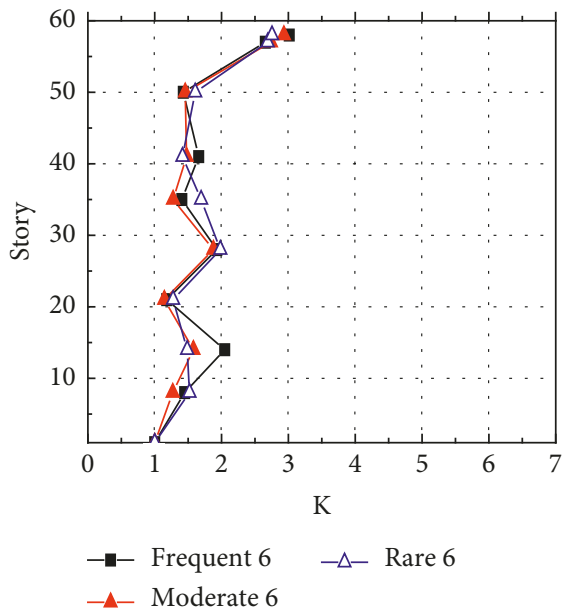

(c)

Figure 6: Envelope of acceleration amplification factor under different earthquake levels: (a) El Centro seismic excitation; (b) Taft seismic excitation; (c) artificial seismic wave (USER1).

TABLE 8: Peak acceleration and acceleration amplification factors.

\begin{tabular}{|c|c|c|c|c|c|c|c|}
\hline \multicolumn{2}{|c|}{ Floor } & \multicolumn{2}{|c|}{ El Centro wave } & \multicolumn{2}{|c|}{ Taft wave } & \multicolumn{2}{|c|}{ Artificial seismic wave } \\
\hline & & $a_{\max }\left(\mathrm{m} / \mathrm{s}^{2}\right)$ & K & $a_{\max }\left(\mathrm{m} / \mathrm{s}^{2}\right)$ & $K$ & $a_{\max }\left(\mathrm{m} / \mathrm{s}^{2}\right)$ & K \\
\hline \multirow{7}{*}{ Frequent 6} & $1^{\text {st }}$ & 0.399 & 1.000 & 0.441 & 1.000 & 0.704 & 1.000 \\
\hline & $14^{\text {th }}$ & 1.223 & 3.061 & 0.889 & 2.013 & 1.443 & 2.050 \\
\hline & $28^{\text {th }}$ & 0.870 & 2.179 & 1.038 & 2.351 & 1.360 & 1.932 \\
\hline & $41^{\text {st }}$ & 0.884 & 2.214 & 0.939 & 2.127 & 1.169 & 1.660 \\
\hline & $50^{\text {th }}$ & 0.643 & 1.610 & 0.628 & 1.422 & 1.006 & 1.429 \\
\hline & Top floor & 1.626 & 4.071 & 1.483 & 3.358 & 1.850 & 2.628 \\
\hline & Roof & 2.027 & 5.076 & 1.898 & 4.298 & 2.124 & 3.016 \\
\hline \multirow{7}{*}{ Moderate 6} & $1^{\text {st }}$ & 0.569 & 1.000 & 0.648 & 1.000 & 0.952 & 1.000 \\
\hline & $14^{\text {th }}$ & 1.710 & 3.005 & 1.331 & 2.054 & 1.502 & 1.578 \\
\hline & $28^{\text {th }}$ & 1.229 & 2.160 & 1.397 & 2.155 & 1.787 & 1.877 \\
\hline & $41^{\text {st }}$ & 1.239 & 2.177 & 1.310 & 2.022 & 1.405 & 1.476 \\
\hline & $50^{\text {th }}$ & 0.824 & 1.448 & 0.845 & 1.304 & 1.387 & 1.456 \\
\hline & Top floor & 2.206 & 3.876 & 2.139 & 3.301 & 2.607 & 2.738 \\
\hline & Roof & 2.678 & 4.705 & 2.680 & 4.135 & 2.792 & 2.932 \\
\hline \multirow{7}{*}{ Rare 6} & $1^{\text {st }}$ & 0.921 & 1.000 & 1.100 & 1.000 & 1.475 & 1.000 \\
\hline & $14^{\text {th }}$ & 1.219 & 1.323 & 1.881 & 1.710 & 2.192 & 1.486 \\
\hline & $28^{\text {th }}$ & 1.484 & 1.611 & 1.965 & 1.786 & 2.925 & 1.982 \\
\hline & $41^{\text {st }}$ & 1.400 & 1.521 & 2.122 & 1.929 & 2.090 & 1.416 \\
\hline & $50^{\text {th }}$ & 1.217 & 1.322 & 1.590 & 1.445 & 2.371 & 1.607 \\
\hline & Top floor & 2.212 & 2.402 & 2.962 & 2.692 & 3.973 & 2.693 \\
\hline & Roof & 3.022 & 3.281 & 3.358 & 3.052 & 4.066 & 2.756 \\
\hline
\end{tabular}


acceleration amplification factor of the same floor continued to decrease with an increasing excitation intensity, reflecting a decreasing structural lateral stiffness and an increasing degree of damage as the seismic intensity increases. However, the decline of the acceleration amplification factor was not obvious after suffering from Rare 6 , which indicated that some lateral-force resisting components of the model have already be damaged. Thus, the experimental phenomenon coincided well with the theory.

4.4. Displacement Response of Prototype Building. The displacement response of the model was converted to the displacement response of the prototype by a similar law. The formula to translate the maximum displacement response from the test model to the prototype building should be as follows:

$$
D_{i}=\frac{\alpha_{\mathrm{mg}} \times D_{\mathrm{mi}} \times S_{d}}{\alpha_{\mathrm{tg}}},
$$

$D_{i}$ is the maximum displacement of the prototype on the $i^{\text {th }}$ floor, $D_{\mathrm{mi}}$ is the maximum displacement of the model at $i^{\text {th }}$ floor, $\alpha_{\mathrm{mg}}$ is the maximum acceleration of the shaking table determined by the similitude law, $\alpha_{\mathrm{ig}}$ is the maximum acceleration of the shaking table measured during the test, and $S_{d}$ is the displacement similarity coefficient.

The maximum displacement and corresponding displacement angle of the prototype structure's roof under different seismic levels are listed in Table 9. It can be seen that as the seismic wave intensity increases, both the maximum displacement and displacement angle of the roof increase. Both the maximum displacement and displacement angle of the prototype structure can meet the requirements of the Chinese code (JGJ3-2010) [12]. The prototype building will not collapse and even have a relatively good integrity after severe earthquake action.

Figure 7 shows the envelope diagrams of maximum displacement in the $Y$ direction of the prototype structure along the floors. It can be seen that the displacements of the prototype structure increase as the stories increase. Furthermore, the effect of the El Centro wave was significantly larger than that of the other two waves. Owning to the whiplash effect, the displacement response of the top floor and roofing layer is much larger than that of other floors. The lateral displacement curves under Frequent and Moderate 6 were not flat, which was small and had obvious bending shear deformation characteristics. So the structure had not been damaged yet. The lateral displacement curves under Rare 6 and 7 were relatively flat and obvious, which means that some components have already been damaged, and the stiffness of the structure has declined.

The story drift of representative floors under different seismic waves is listed in Table 10. It can be seen that all the maximum story drift of the structure occurred in the top of the structure, especially on the $56^{\text {th }}$ floor, which means that the upper part of the structure is relatively weaker than others. The stiffness is reduced as the structure becomes smaller above $41^{\text {st }}$ floors, which leads to the increase of story drift. All story drifts of the structure under the testing earthquakes are smaller than the value specified in the Chinese code (JGJ3-2010) [12], which indicates that the structure can meet the seismic resistance requirements of the code.

4.5. Torsion Effect. There are symmetrical accelerometers arranged at the $41^{\text {st }}$ and the top floor. The displacements under different seismic intensities of these two stories can be obtained by integrating the accelerations. Hence, the torsion can be obtained by the ratios of the displacements to the sensors' distances. Torsion angle of the model under different seismic levels is shown in Figure 8. It can be seen that the torsion deformation is small before the inputting of Rare 6 , reflecting a good torsional stiffness. However, the torsion deformation became larger under Rare 7, which indicates that some part of the structure has been damaged.

According to transformation formula, the hysteresis curve of the prototype structure under different earthquake levels can be obtained by the displacement historical response and shear historical responses. The shear responses can be calculated by quality distribution of floors and corresponding acceleration responses. Taking Rare 6 as an example, considering the limited pages of this paper, the hysteresis curve under different waves is shown in Figure 9. Actually, the hysteresis curve of the structure under Frequent, Moderate, and Rare 6 change with the external excitation while the change of stiffness is however not obvious, which indicates that the building is basically in the elastic working stage. However, it can be seen that the hysteresis curve becomes irregular under Rare 7, which indicates that some parts of the structure have already been damaged and the structure has gone into the elastic-plastic phase.

\section{Finite Element Analysis}

In order to verify the experimental results, a finite element model of the test model was established by ANSYS. Elasticplastic analysis of the test model was conducted. Threedimensional BEAM4 element was used to simulate the beams and embedded columns, and SHELL63 was used to simulate the floors and shear walls. The material properties were obtained from the measured tests, and the nonlinear performance of materials had been considered. The input seismic waves used in the finite element model were the same as the shaking table test. Real properties of the materials of the model had been taken into account. The finite element mode contained 78899 nodes, beam elements 4599, and shell elements 72414 totally. The height is $179.4 \mathrm{~m}$, which is the same as the prototype building.

5.1. Dynamic Characteristic. The results of the finite element analysis indicate that first three order vibration modes of the model include the translation mode in $Y$ direction, $X$ direction, and torsion mode. The first three order vibration modes are shown in Figure 10. All the three vibration modes reflect the coupling between translation and torsion.

Table 11 shows the free vibration characteristics of the model in experimental results and finite element 
TABLE 9: Maximum displacement and displacement angle of the roof of the prototype building.

\begin{tabular}{lcccc}
\hline Seismic intensity & Test condition & Seismic wave & Displacement of vertex $(\mathrm{m})$ & Displacement angle of vertex \\
\hline \multirow{4}{*}{ Frequent 6 } & Condition 2 & El Centro wave- $Y$ direction & 0.016 & $1 / 4654$ \\
& Condition 3 & Taft wave- $Y$ direction & 0.010 & $1 / 7670$ \\
& Condition 4 & Artificial seismic wave- $Y$ direction & 0.008 & $1 / 9848$ \\
\hline \multirow{2}{*}{ Moderate 6 } & Condition 6 & El Centro wave- $Y$ direction & 0.043 & $1 / 1573$ \\
& Condition 7 & Taft wave- $Y$ direction & 0.026 & $1 / 2642$ \\
& Condition 8 & Artificial seismic wave- $Y$ direction & 0.023 & $1 / 2932$ \\
\hline \multirow{2}{*}{ Rare 6 } & Condition 10 & El Centro wave- $Y$ direction & 0.060 & $1 / 953$ \\
& Condition 11 & Taft wave- $Y$ direction & 0.048 & $1 / 1196$ \\
\hline \multirow{2}{*}{ Rare 7 } & Condition 12 & Artificial seismic wave- $Y$ direction & 0.052 & $1 / 1110$ \\
& Condition 14 & El Centro wave- $Y$ direction & 0.139 & $1 / 456$ \\
\hline
\end{tabular}

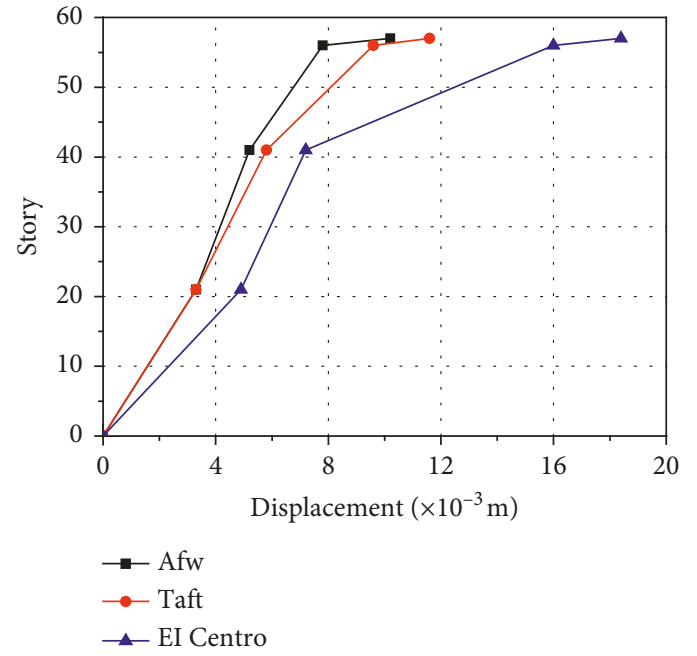

(a)

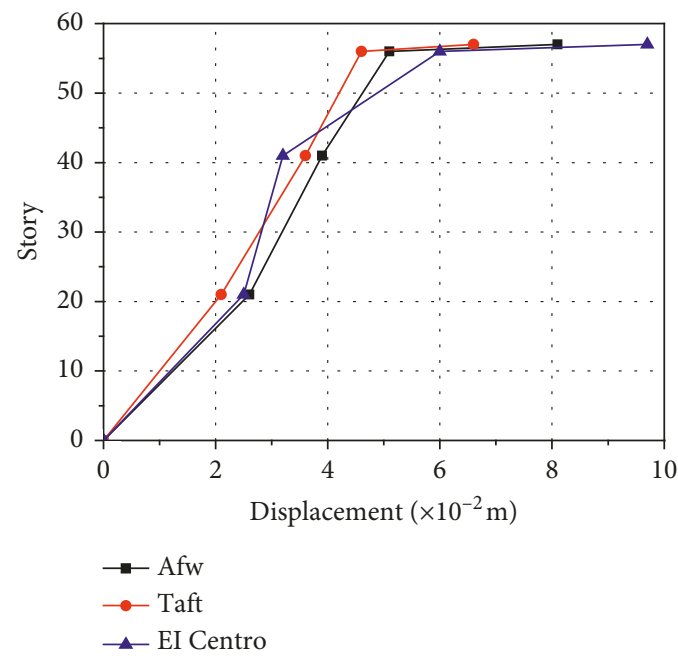

(c)

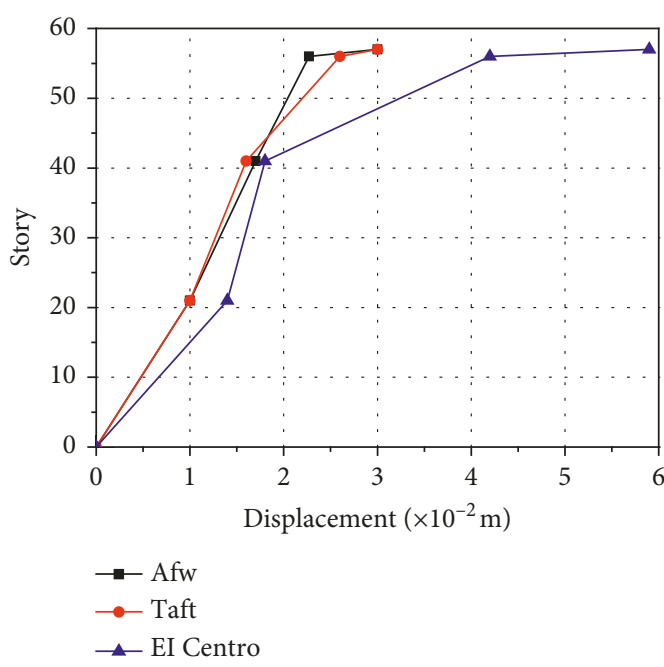

(b)

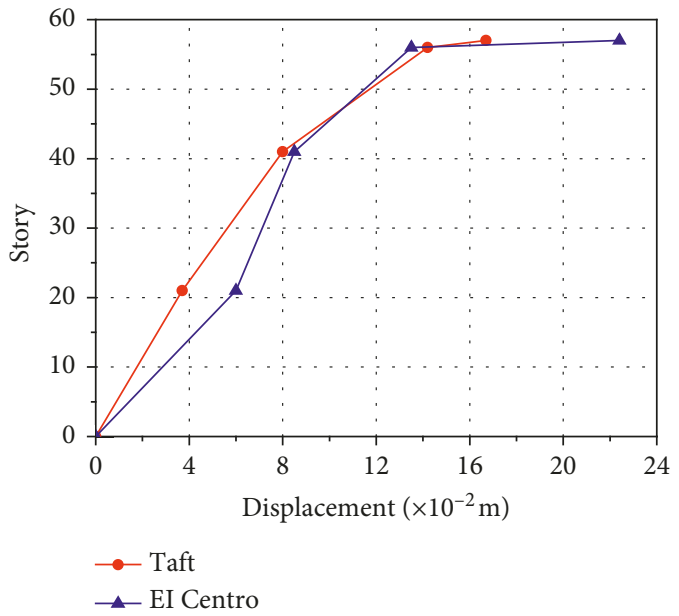

(d)

Figure 7: Envelope of relative displacement under different earthquake levels: (a) Frequent 6; (b) Moderate 6; (c) Rare 6; (d) Rare 7.

simulation results. It can be seen that the finite element simulation result of the first periods and second periods is similar to those of experiment results, and divergences between the two are $0.07 \%$ and $2.41 \%$, respectively.
However, the divergences of the third periods became much more significant, which is still within an acceptable level. The ratio of the first mode periods between torsion and translation in the $Y$ direction is 0.38 in the finite 
TABLE 10: Story drift of the structure under different seismic waves.

\begin{tabular}{|c|c|c|c|c|}
\hline Seismic intensity & Seismic wave & $20^{\text {th }}$ floor & $41^{\text {st }}$ floor & $56^{\text {th }}$ floor (top) \\
\hline \multirow{3}{*}{ Frequent 6} & El Centro & 0.045 & 0.069 & 0.159 \\
\hline & Taft & 0.039 & 0.06 & 0.096 \\
\hline & Artificial & 0.039 & 0.054 & 0.075 \\
\hline \multirow{3}{*}{ Moderate 6} & El Centro & 0.141 & 0.189 & 0.432 \\
\hline & Taft & 0.099 & 0.165 & 0.258 \\
\hline & Artificial & 0.099 & 0.177 & 0.234 \\
\hline \multirow{3}{*}{ Rare 6} & El Centro & 0.255 & 0.324 & 0.603 \\
\hline & Taft & 0.219 & 0.351 & 0.48 \\
\hline & Artificial & 0.276 & 0.384 & 0.519 \\
\hline
\end{tabular}

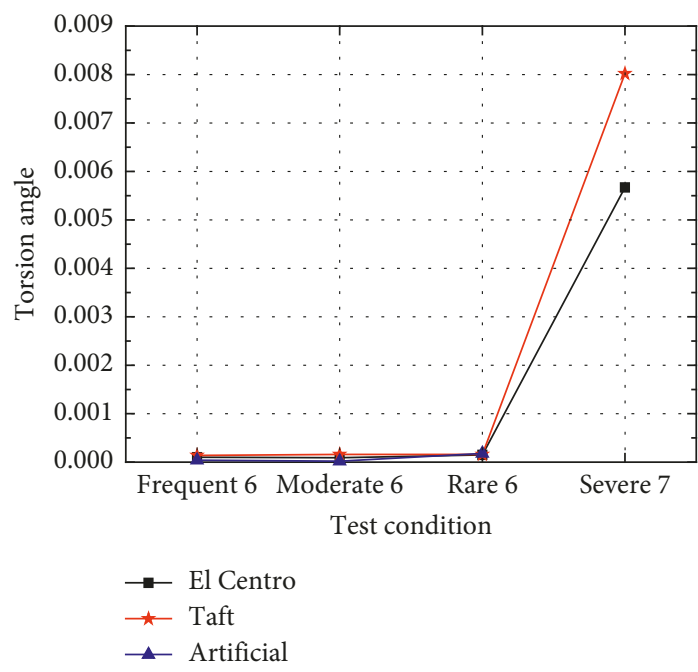

(a)

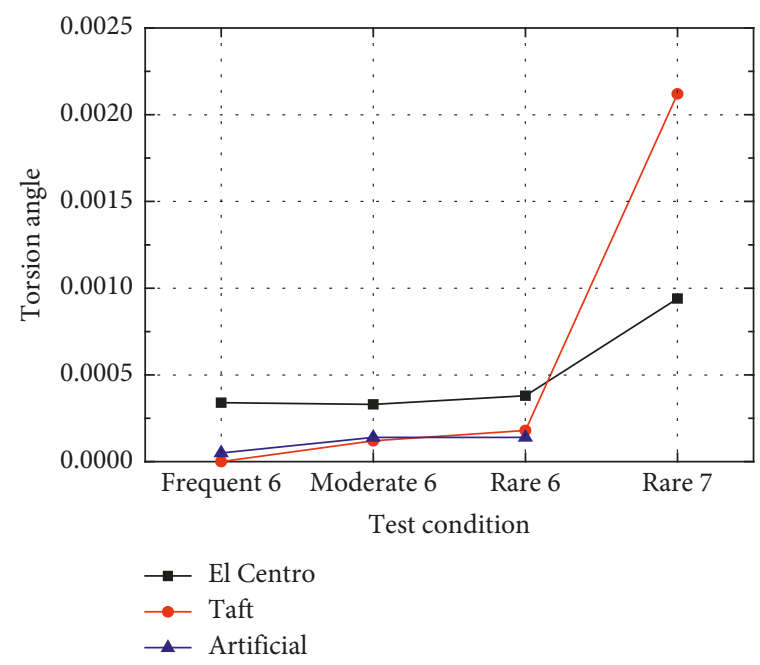

(b)

Figure 8: Torsion angle under different floors: (a) $41^{\text {st }}$ floor; (b) $51^{\text {st }}$ floor.

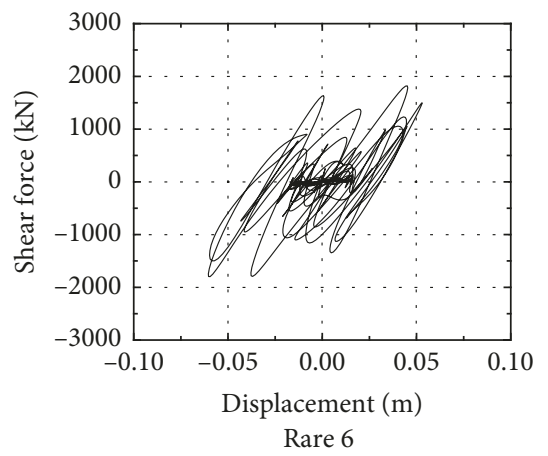

(a)

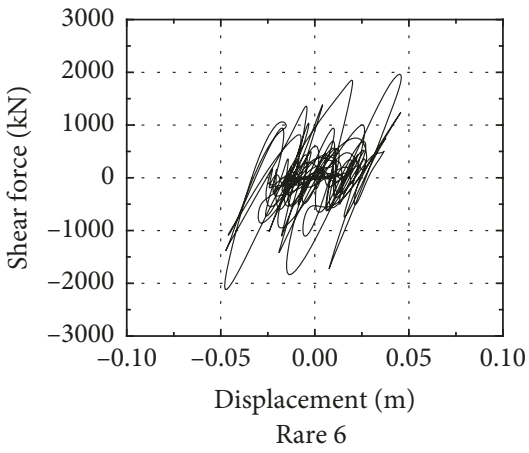

(b)

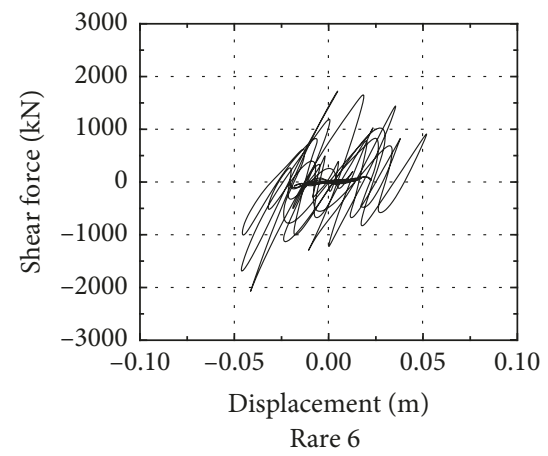

(c)

FiguRE 9: Hysteresis curve of the prototype structure under different waves: (a) El Centro wave; (b) Taft wave; (c) artificial seismic wave.

element simulation, while the test result is 0.33 . Both the two results are far less than the limited value of the Chinese code (JGJ3-2010) [12]. Moreover, the influence of higher vibration modes to the structure can be quite large because of the high aspect ratio for high-rise buildings. It is usually difficult to capture the higher vibration modes of the building by an experiment, and the computational analysis thus shows its advantage and is an important supplement. The first 30 vibration modes and periods were analyzed through the finite element method. It can be concluded that the vibration modes became localized after the $15^{\text {th }}$ order, and the vibration of the top model is much more obvious than others, which indicates that the whiplash effect is quite remarkable. Based on mass participation ratio and vibration maps, it can be concluded that the vibration mode of the structure is coupled translation and torsion, and the torsion has great influence on the seismic response of the structure. 


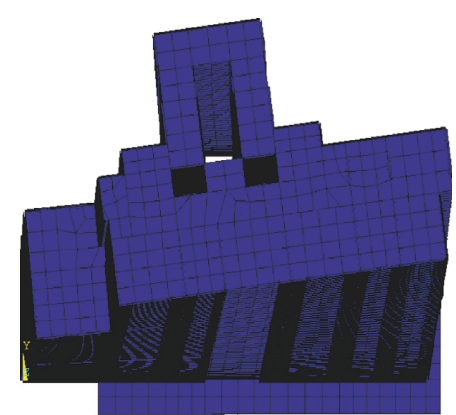

(a)

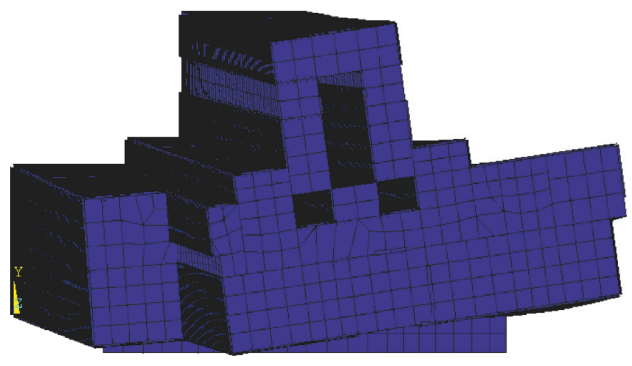

(b)

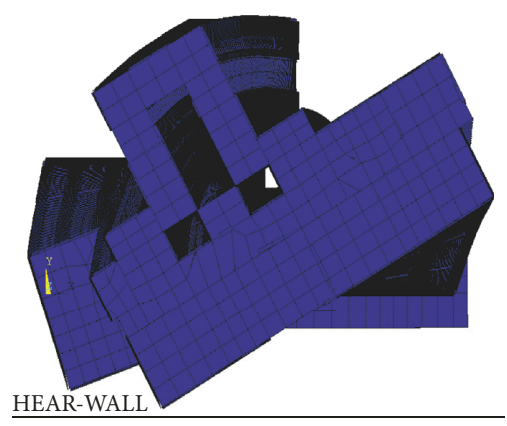

(c)

FIgURE 10: First three vibration modes: (a) $1^{\text {st }}$ ( $Y$ direction); (b) $2^{\text {nd }}$ ( $X$ direction); (c) $3^{\text {rd }}$ (torsion).

TABLE 11: Comparison of free vibration characteristics.

\begin{tabular}{|c|c|c|c|c|c|}
\hline \multirow{2}{*}{\multicolumn{2}{|c|}{ Vibration mode }} & \multicolumn{2}{|c|}{ Experimental result } & \multicolumn{2}{|c|}{ Finite element result } \\
\hline & & Frequency $(\mathrm{Hz})$ & Period (s) & Frequency $(\mathrm{Hz})$ & Period (s) \\
\hline \multirow{2}{*}{$Y$ Direction } & $1^{\text {st }}$ order & 2.54 & 0.3937 & 2.5348 & 0.394 \\
\hline & $2^{\text {nd }}$ order & 12.11 & 0.0826 & 9.7863 & 0.102 \\
\hline \multirow{2}{*}{$X$ direction } & $1^{\text {st }}$ order & 3.71 & 0.2695 & 3.8012 & 0.263 \\
\hline & $2^{\text {nd }}$ order & - & - & 12.833 & 0.077 \\
\hline \multirow{2}{*}{ Torsion } & $1^{\text {st }}$ order & 7.62 & 0.1312 & 6.6293 & 0.151 \\
\hline & $2^{\text {nd }}$ order & 21.30 & 0.0469 & 27.641 & 0.036 \\
\hline
\end{tabular}

5.2. Acceleration Response. Table 12 shows the maximum acceleration amplification factor in the main vibration direction ( $Y$ direction) under different seismic levels, and both the measured and calculated values are listed.

It can be seen in Table 12 that both the acceleration amplification factor of the finite element model and experimental model continued to decrease after suffering from Frequent 6, Moderate 6, and Rare 6, reflecting that the lateral stiffness of the structure has decreased and the damage of the structure increased. The acceleration response of finite element simulation is similar to the shaking table test.

5.3. Displacement Response. In order to compare the experimental results with the calculated results, the maximum displacement of the test floors under different earthquake levels is listed in Table 13. The envelope of interstory drift under different earthquake waves is shown in Figure 11.

It can be calculated that both the story drift angle of the finite element model and test model under Frequent and Moderate 6 can meet the seismic resistance requirements in the code specification (1/800). The maximum story drift angle of the finite element model under Rare 6 is $1 / 350$, which is larger than the limited elastic value; however, it still can meet the requirements of plastic story drift angle in the Chinese code (JGJ3-2010) [12]. As can be seen in Figure 11, all the peak story drift occurs in the upper part of the structure, especially near the $50^{\text {th }}$ floor, which is relatively weaker than the other parts of the structure. Furthermore, story drift has increased above $41^{\text {st }}$ floors, reflecting a decline of the stiffness, which coincides well with the experimental analysis. Hence, we can reach the conclusion that all the results of finite element simulation coincides well with the results of the experiment, which indicates that both the finite element simulation, and the shaking table model test are reasonable.

\section{Damage Identification}

In this section, an identification method based on the AR model is presented to identify the damage location and degree of the test model after suffering from simulated earthquakes. Firstly, the AR model is briefly introduced and established by the acceleration response of the test model. Secondly, the plain version of the least squares (LS) method is used to solve the unknown parameters of the established AR model. Then, a judging factor based on the residual variance of the $A R$ model is proposed to estimate the degree of structural damage. Finally, the proposed damage factor of the model building after different earthquake intensities is calculated by MATLAB. The damage location and degree identified by this method are compared with the testing results as well as the numerical results.

6.1. AR Model and Parameter Identification. The AR model is widely used in the field of structural damage identification [18], and it is attempt to account for the correlations of the current time parameter with its predecessors in time series, in which the output variable depends linearly on its own previous values and on a stochastic term. It can be implemented to represent the dynamic response of structures [19]. The AR model does not need any specific structural characteristics but the output response data; 
TABLE 12: Comparison of maximum acceleration amplification factor in the $Y$ direction.

\begin{tabular}{lccr}
\hline \multirow{2}{*}{ Seismic intensity } & Input seismic wave & \multicolumn{2}{c}{ Maximum acceleration amplification factor } \\
& & Experimental value & 5.34 \\
Frequent 6 & El Centro & 5.90 & 5.13 \\
& Taft & 4.94 & 4.68 \\
\hline \multirow{3}{*}{ Moderate 6 } & Artificial & 3.83 & 4.01 \\
& El Centro & 3.44 & 3.14 \\
& Taft & 3.16 & 3.11 \\
Rare 6 & Artificial & 3.12 & 3.26 \\
& El Centro & 2.29 & 2.57 \\
\hline
\end{tabular}

Table 13: Comparison of maximum displacements $(\mathrm{cm})$

\begin{tabular}{|c|c|c|c|c|c|c|c|}
\hline \multirow{2}{*}{$\begin{array}{l}\text { Seismic } \\
\text { intensity }\end{array}$} & \multirow{2}{*}{$\begin{array}{l}\text { Seismic } \\
\text { wave }\end{array}$} & \multicolumn{2}{|c|}{$20^{\text {th }}$ floor } & \multicolumn{2}{|c|}{$41^{\text {st }}$ floor } & \multicolumn{2}{|c|}{$56^{\text {th }}$ floor (top) } \\
\hline & & $\begin{array}{l}\text { Experimental } \\
\text { value }\end{array}$ & $\begin{array}{l}\text { Numerical } \\
\text { value }\end{array}$ & $\begin{array}{l}\text { Experimental } \\
\text { value }\end{array}$ & $\begin{array}{l}\text { Numerical } \\
\text { value }\end{array}$ & $\begin{array}{l}\text { Experimental } \\
\text { value }\end{array}$ & $\begin{array}{c}\text { Numerical } \\
\text { value }\end{array}$ \\
\hline \multirow{3}{*}{ Frequent 6} & El Centro & 0.15 & 0.18 & 0.23 & 0.25 & 0.53 & 0.64 \\
\hline & Taft & 0.13 & 0.14 & 0.2 & 0.22 & 0.32 & 0.57 \\
\hline & Artificial & 0.13 & 0.16 & 0.18 & 0.19 & 0.25 & 0.46 \\
\hline \multirow{3}{*}{ Moderate 6} & El Centro & 0.47 & 0.51 & 0.63 & 0.71 & 1.44 & 1.52 \\
\hline & Taft & 0.33 & 0.35 & 0.55 & 0.65 & 0.86 & 1.23 \\
\hline & Artificial & 0.33 & 0.31 & 0.59 & 0.62 & 0.78 & 1.01 \\
\hline \multirow{3}{*}{ Rare 6} & El Centro & 0.85 & 0.92 & 1.08 & 1.12 & 2.01 & 2.34 \\
\hline & Taft & 0.73 & 0.80 & 1.17 & 1.15 & 1.6 & 2.02 \\
\hline & Artificial & 0.92 & 0.88 & 1.28 & 1.07 & 1.73 & 1.91 \\
\hline
\end{tabular}

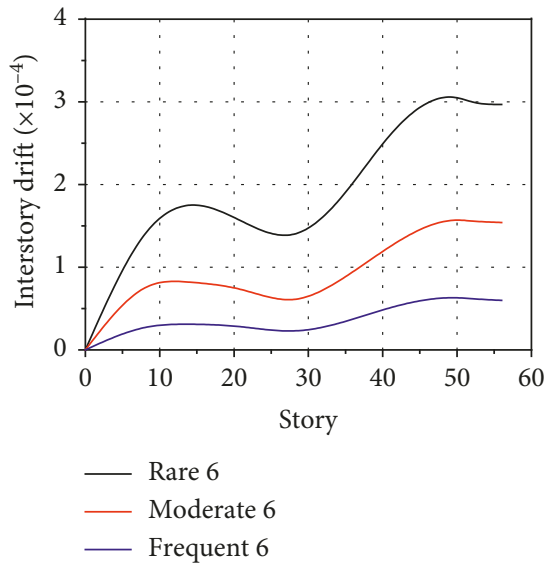

(a)

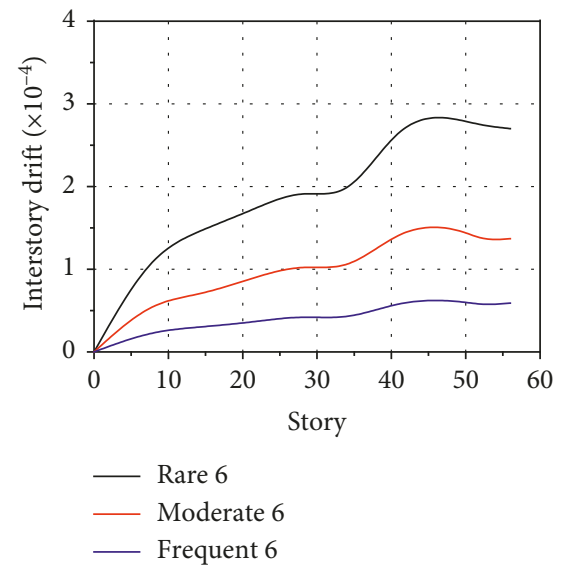

(b)

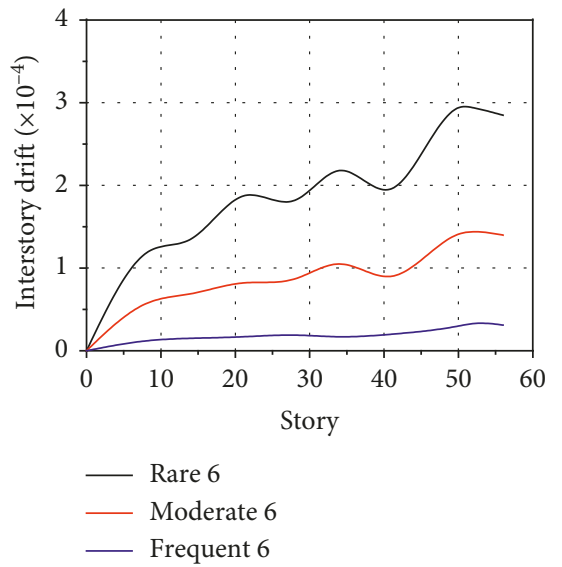

(c)

FIGURE 11: Envelope diagrams of story drift under different earthquake waves: (a) El Centro wave; (b) Taft wave; (c) artificial seismic wave.

hence, it is widespread for complex structures [20, 21]. In this research, the AR time-series model is used to describe the acceleration time histories of the shaking table. A noisy AR model of order $m$ is described by equation [22]:

$$
x_{t}=\beta_{1} x_{t-1}+\beta_{2} x_{t-2}+\cdots+\beta_{m} x_{t-m}+e_{x t},
$$

where $x_{t}$ is the output of the AR model, it is the discrete-time signal, and in this paper, the acceleration responses are used. $e_{x t}$ is the random noise. $m$ is the unknown order of this model at prior and varies from 0 to $t-1 . \beta$ denotes the AR coefficients, which need to be estimated. This model can be simplified as follows [23]:

$$
y=A \beta+v
$$

where $y=\left[x_{t}, x_{t-1}, \cdots, x_{t-m+1}\right]^{T}, \beta=\left[\beta_{1}, \beta_{2}, \cdots, \beta_{m}\right]^{T}$, and $v=\left[e_{x t}, e_{x(t-1)}, \cdots, e_{x(t-m+1)}\right]^{T}$.

In this paper, a famous approach the least square (LS) method is used to estimate unknown vector $\beta$. It is solved by 
the Lagrange Extremum Method, and the estimation result is shown as follows [24]:

$$
\widehat{\beta}=\left(A^{T} W A\right)^{-1} A^{T} W y .
$$

Estimated residual is as follows:

$$
v=A \widehat{\beta}-y .
$$

However, finding out the optimal order $m$ of the AR model is not trivial. The order is not as larger as better. When the order of the AR model increases, the residual sum of squares theoretically decreases, while the calculating errors rise. Therefore, these two aspects should be both considered in the modeling. In literature, there are some criterions achieved this goal [25], such as Akaike's Information Criterion (AIC) or Bayesian information criterion (BIC), proposed by Akaike and Schwarz, respectively. The AIC will be used in this paper, and it is presented as follows:

$$
\operatorname{AIC}(n)=\ln \widehat{\sigma}_{a}^{2}(n)+\frac{2 n}{N},
$$

where $\widehat{\sigma}_{a}^{2}$ is the estimated variance of residual errors when the order of the AR model is $n$.

6.2. Damage Factor. After the unknown parameter $\beta$ of the AR model is obtained, a factor needs to be proposed to judge the damage of the structure. The step of the method can be clarified as follows:

(1) Dividing the obtained response acceleration data before damage into two parts, part $A_{0}$ and part $B_{0}, A_{0}$ serves as benchmark data, from which $\beta_{0}$ of the undamaged situation will be estimated. While $B_{0}$ serves as the unknown inspection data to be estimated in the healthy state of structure.

(2) Estimating $\beta_{0}$ by equation (5) and the residential $v_{0}$ of $B_{0}$ based on $\beta_{0}$ by equation (6).

(3) Dividing all the observed data into part $A_{i}$ and $B_{i}$. Estimating the residential $v_{A_{i}}$ of $A_{i}$ and $v_{B_{i}}$ of $B_{i}$ based on the obtained $\beta_{0}$.

(4) Calculating the average of $v_{A_{i}}$ and $v_{B_{i}}$ to obtain $v_{i} \cdot v_{i}$ represents the final residential of $i^{\text {th }}$ observed data to be estimated after damage.

(5) The damage identification factor is calculated as the ratio between the residential variance of $v_{i}$ to $v_{0}$, shown as

$$
\mathrm{IF}=\frac{\sigma^{2}\left(v_{i}\right)}{\sigma^{2}\left(v_{0}\right)}
$$

It is clear that if the data to be estimated is coming from the undamaged structure, IF will be close to one. Otherwise, $\sigma^{2}\left(\nu_{i}\right)$ will be larger than $\sigma^{2}\left(\nu_{0}\right)$; that is, the IF will increase as the damages of the structure rise.

6.3. Identification Results. In this part, the IF of different stories and seismic intensities will be presented. It can be seen in Table 6 that before and after all the testing waves, the white noise is used to test the model; hence, the identification of white noise will be conducted here. Figure 12 lists the IF after different earthquake intensities of some representing floors based on the white noise excitation. It can be concluded that the IF becomes larger as the intensity of earthquake increases, indicating that the damage of the test building rises while intensity increases. Furthermore, the IF of the top story is larger than that of other stories, reflecting the whiplash effect too.

When comparing the damages of all stories after the same seismic intensity, the damage variation along stories can be studied. For the sake of simplicity, Figure 13 shows the IF along some stories, taking the white noise response after suffering from Frequent 6 and Rare 7 as examples here.

It can be concluded that after Frequent 6 , all the IF ranges from 1.0 to 1.25 , indicating very little damages occurred in the model building. Even though the IF of the $1^{\text {st }}$ floor and top floor is the smallest and largest respectively, there is only a little difference. However, after suffering from Rare 7, the damage increases obviously, the damage degree of $50^{\text {th }}, 52^{\text {nd }}$, and top floors is larger than that of other floors, and the damage of $14^{\text {th }}, 28^{\text {th }}$, and $8^{\text {th }}$ stories is quite significant as well, while the damage of the first story is the smallest. This variation can also be found in Table 8 of the peak acceleration and acceleration amplification factors. The IF of $41^{\text {st }}$ floor is not quite large but increased rapidly above $41^{\text {st }}$ floor, indicating that the $41^{\text {st }}$ floor is not in a serious damage condition as the floors above. This is not limited to the earthquake intensities in Figure 13, and the same conclusion can be drawn after analyzing all the white noise response data of the model building.

Moreover, after studying the IF of the three types of waves used in the test, the variation of IF is nearly the same with that of white noise, and the results will not be detailed here. However, the comparison of the effectiveness between different types of waves cannot be obtained, probably due to no relative data to be used to calculate the healthy residential of benchmark data $\left(\nu_{i}\right)$.

To summarize, we can reach the conclusion that the identification results are reasonable and coincide well with the results of the experiment and numerical simulation, which indicates that the identification method presented here is effective, and not only the location but also the degree of the damage can be identified by the new identification factor.

\section{Conclusion}

The prototype building is represented as the testing model in this paper. Based on all the analysis, it can be concluded that after Frequent 6, almost no changes occur in the structure which is still in the elastic stage. After Moderate 6 , no visible damages occur, and natural frequency decreased slightly, which indicates that the stiffness of the prototype building was changed slightly in this condition. However, under Rare 6 , the $1^{\text {st }}$ natural frequency decreased by $3.9 \%$ and other parameters had little of changes, which suggests that some part of the prototype building will be 


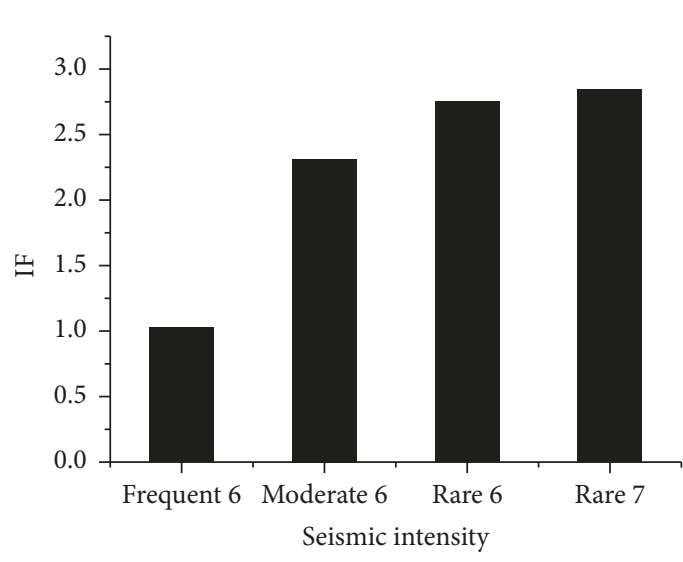

IF of $1^{\text {st }}$ floor

(a)

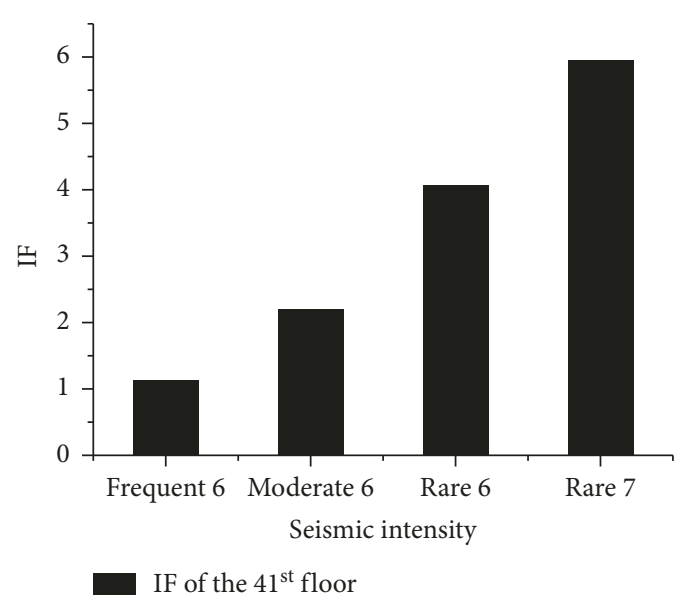

(c)

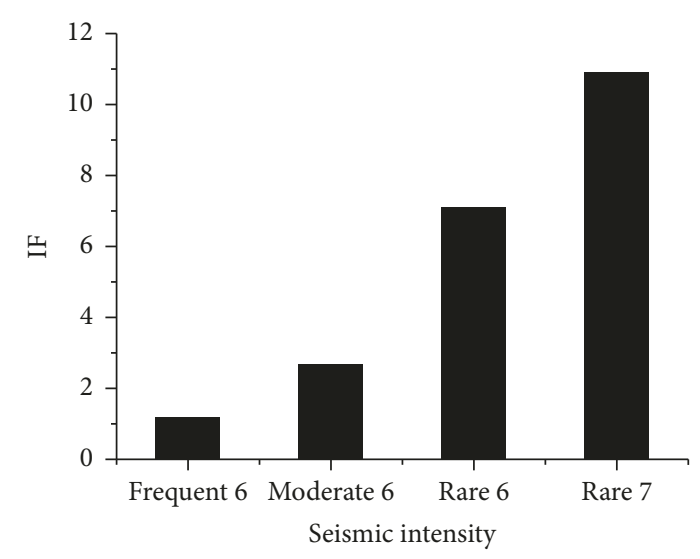

(b)

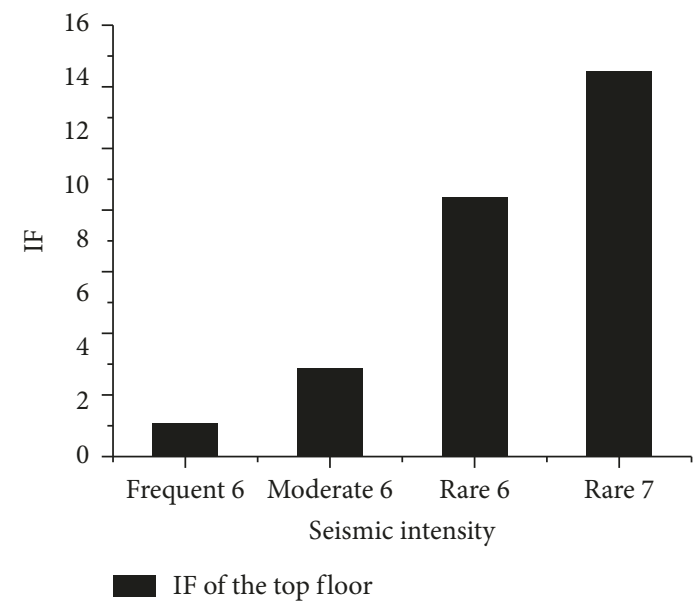

(d)

FIGURE 12: IF of some floors after different earthquake intensities: (a) $1^{\text {st }}$ floor; (b) $8^{\text {th }}$ floor; (c) $41^{\text {st }}$ floor; (d) top floor.

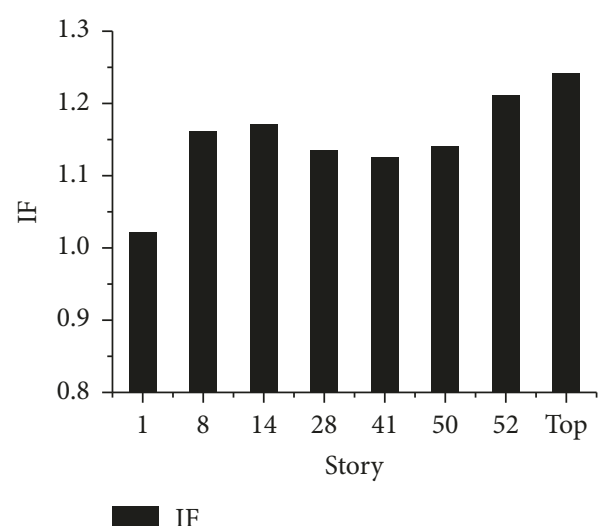

(a)

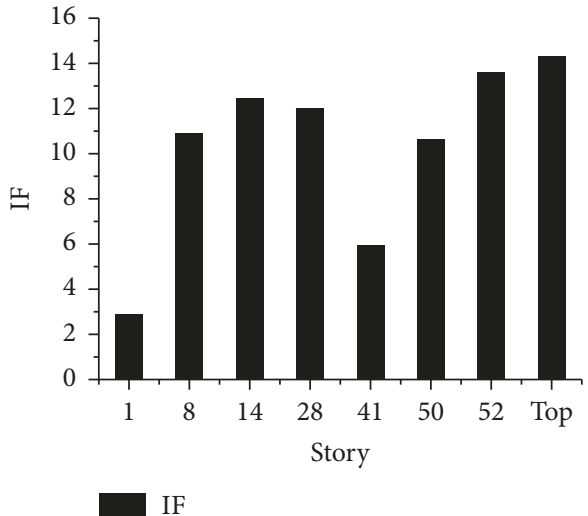

(b)

FIgURe 13: IF along stories: (a) Frequent 6; (b) Rare 7.

damaged in this condition. Under Rare 7, visible cracks and spalling of concrete occur, and the natural frequency of the model decreased significantly, which means that the prototype building has been damaged significantly in this condition.
Acceleration response of the top part of the structure is relatively large, which indicates that the whiplash effect of the building is significant. The torsional deformation is not apparent when an earthquake is small, but it became more substantial when the level of input earthquake 
increased, which indicates that the effect of torsion on seismic response of the structure is increased. Furthermore, the effect of torsion is large above the $41^{\text {st }}$ floors, especially on the $52^{\text {nd }}$ floor, showing that these floors may be weaker than other parts relatively. However, as for the same level of earthquake intensity, the maximum displacement, displacement angle, story drift, and torsional angle of the model caused by the El Centro wave are the largest among the three types of input waves, followed by the Taft wave and artificial seismic wave. Thus the El Centro wave may be the most dangerous wave to the prototype building.

Finite element simulation results coincide well with the experimental results. Higher vibration modes of the building show that vibration modes have become localized after $15^{\text {th }}$ order, and the vibration mode of the structure is translationtorsion coupled; the whiplash effect at the top of the structure is quite remarkable.

The damage degree and location identified by the proposed factor in this paper also show that the upper part of the building has more damage than the lower part, but the damage of $8^{\text {th }} \sim 28^{\text {th }}$ floor is also quite significant. With the increase of the earthquake acceleration, the damage of the building increases apparently. The identification results indicate that the identification method is effective and can be used in other similar cases.

The results of the test, the numerical analysis, and the identification prove that the building in the A2 block developed by Wuhan Shimao Group was designed reasonably, which can entirely meet the requirement in the Chinese Code and can be safely put into use. Even though the design of this building can meet the seismic design requirements, some measures should be taken to improve the seismic performances. Firstly, the connection between the shear wall of the bottom floor and the base can be strengthened to avoid horizontal joined-up cracks under big earthquakes. Then, the effect of torsion is large above the $41^{\text {st }}$ floor of the building, but the damage of the $8^{\text {th }} \sim 28^{\text {th }}$ floor cannot be neglected either. More structural reinforcements may be necessary for these floors. The top of the structure also needs to be strengthened since the whiplash effect is obvious.

\section{Data Availability}

The data of this study are available from the corresponding author upon request.

\section{Conflicts of Interest}

The authors declare that there are no conflicts of interest regarding the publication of this paper.

\section{Acknowledgments}

This work was supported by the National Natural Science Foundation of China (NSFC) (grant no. 51678464) and the China Government Scholarship Council (CSC no. 201706950038).

\section{References}

[1] H. Aoyama, Design of Modern High-Rise Reinforced Concrete Structures, Imperial College Press, London, UK, 2001.

[2] X. Zhou and G. Li, "Shaking table model test of a steelconcrete composite high-rise building," Journal of Earthquake Engineering, vol. 14, no. 4, pp. 601-625, 2010.

[3] P. Martinelli and F. C. Filippou, "Simulation of the shaking table test of a seven-story shear wall building," Earthquake Engineering \& Structural Dynamics, vol. 38, no. 5, pp. 587607, 2009.

[4] M. Saranik, D. Lenoir, and L. Jézéquel, "Shaking table test and numerical damage behaviour analysis of a steel portal frame with bolted connections," Computers \& Structures, vol. 112113, no. 4, pp. 327-341, 2012.

[5] G. Chen, Z. Wang, X. Zuo, X. Du, and H. Gao, "Shaking table test on the seismic failure characteristics of a subway station structure on liquefiable ground," Earthquake Engineering \& Structural Dynamics, vol. 42, no. 10, pp. 1489-1507, 2013.

[6] Y.-1. Lin, W.-m. Leng, G.-l. Yang, L. Li, and J.-S. Yang, "Seismic response of embankment slopes with different reinforcing measures in shaking table tests," Natural Hazards, vol. 76, no. 2, pp. 791-810, 2015.

[7] N. Srilatha, G. Madhavi Latha, and C. G. Puttappa, "Effect of frequency on seismic response of reinforced soil slopes in shaking table tests," Geotextiles and Geomembranes, vol. 36, no. 1, pp. 27-32, 2013.

[8] W. G. Liu, C. Qin, Y. Liu et al., "Shaking table tests on earthquake response characterization of a complex museum isolated structure in high intensity area," Shock and Vibration, vol. 2016, Article ID 7974090, 23 pages, 2016.

[9] X. Lu, Y. Zou, W. Lu, and B. Zhao, "Shaking table model test on Shanghai world financial center tower," Earthquake Engineering \& Structural Dynamics, vol. 36, no. 4, pp. 439-457, 2007.

[10] D. G. Lignos, Y. Chung, T. Nagae, and M. Nakashima, "Numerical and experimental evaluation of seismic capacity of high-rise steel buildings subjected to long duration earthquakes," Computers \& Structures, vol. 89, no. 11-12, pp. 959-967, 2011.

[11] F. Graziotti, U. Tomassetti, S. Kallioras, A. Penna, and G. Magenes, "Shaking table test on a full scale URM cavity wall building," Bulletin of Earthquake Engineering, vol. 15, no. 12, pp. 5329-5364, 2017.

[12] National Standard, Technical Specification for Concrete Structures of High-rise Building (JGJ3-2010), Beijing, China, 2010.

[13] National Standard, Tall building Earthquake-Proof Engineering Special Review of Technical Points (No. 65), Beijing, China, 2015.

[14] G. Rastogi, K. Moin, and S. M. Abbas, "Dimensional analysis and development of similitude rules for dynamic structural models," International Journal of Emerging Technology and Advanced Engineering, vol. 5, no. 3, pp. 68-72, 2015.

[15] National Standard, Standard for Test Methods of Concrete Structures (GB50152-2012), Beijing, China, 2012.

[16] National Standard, Seismic Ground Motion Parameters Zonation of China, Beijing, China, 2016.

[17] National Standard, Code of Seismic Design of Buildings (GB50011-2010), Beijing, China, 2010.

[18] G. Mustafa, Investigation of Damage detection Methodologies for Structural Health Monitoring, Boğaziçi University, Istanbul, Turkey, 2009. 
[19] M. Krishnan, B. Bhowmik, B. Hazra, and V. Pakrashi, "Real time damage detection using recursive principal components and time varying auto-regressive modeling," Mechanical Systems and Signal Processing, vol. 101, pp. 549-574, 2018.

[20] R. Yao and S. N. Pakzad, "Autoregressive statistical pattern recognition algorithms for damage detection in civil structures," Mechanical Systems and Signal Processing, vol. 31, pp. 355-368, 2012.

[21] A. Datteo, G. Busca, G. Quattromani, and A. Cigada, "On the use of AR models for SHM: a global sensitivity and uncertainty analysis framework," Reliability Engineering \& System Safety, vol. 170, pp. 99-115, 2018.

[22] J. Hamilton, Time Series Analysis, Princeton University Press, Princeton, NJ, USA, 1994.

[23] P. Xu, J. Liu, and C. Shi, "Total least squares adjustment in partial errors-in-variables models: algorithm and statistical analysis," Journal of Geodesy, vol. 86, no. 8, pp. 661-675, 2012.

[24] W. E. Deming, "XI.The application of least squares," The London, Edinburgh, and Dublin Philosophical Magazine and Journal of Science, vol. 11, no. 68, pp. 146-158, 1931.

[25] W. Chen, Autoregressive Model Estimation Theory and its Application in Deformation Monitoring Data Processing, Wuhan University, Wuhan, Hubei, China, 2013. 


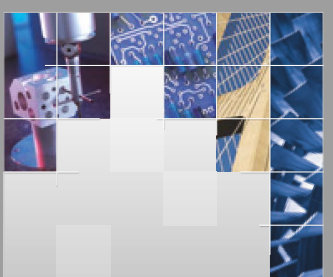

\section{Enfincering}
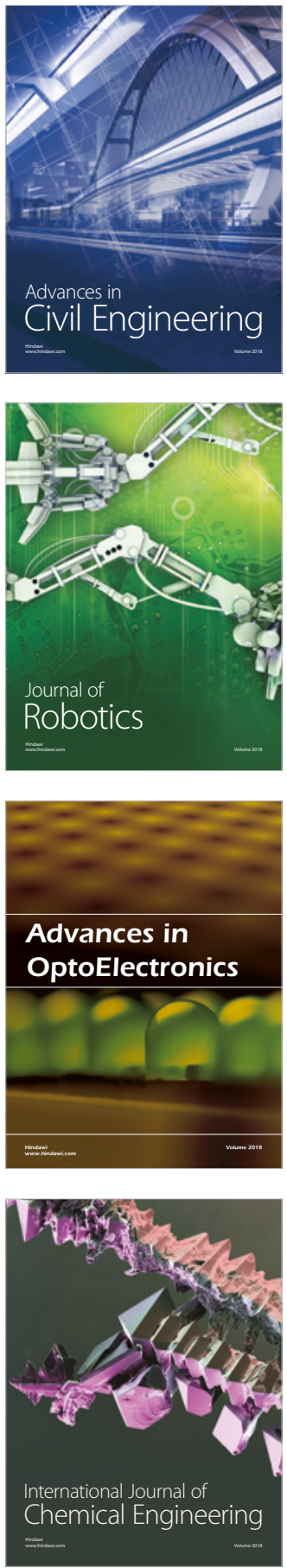

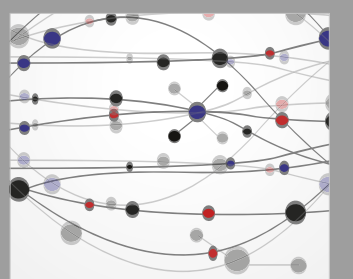

\section{Rotating \\ Machinery}

The Scientific World Journal

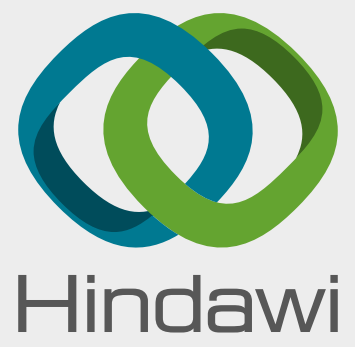

Submit your manuscripts at

www.hindawi.com
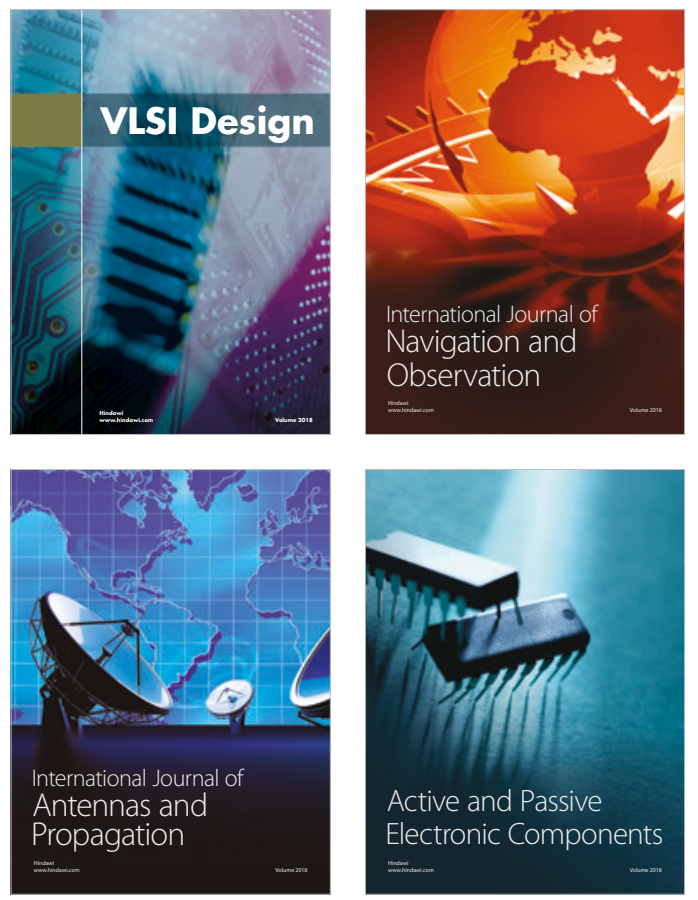
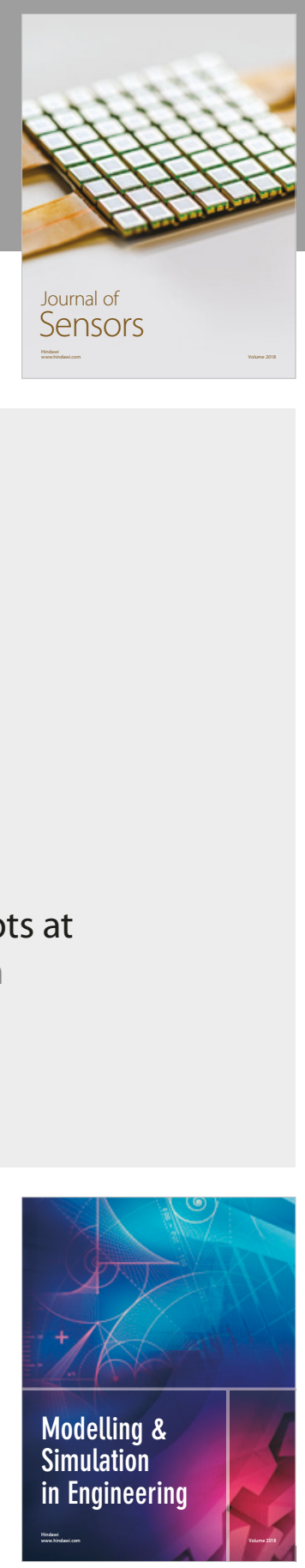

\section{Advances \\ Multimedia}
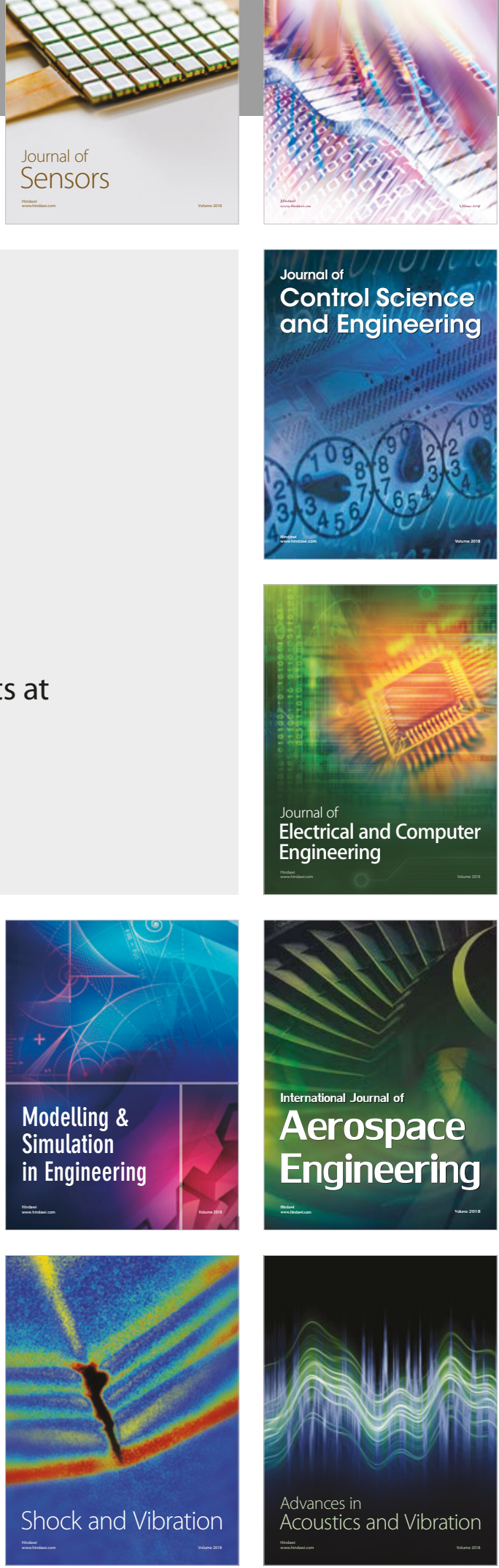